\title{
WestVirginiaUniversity
}

THE RESEARCH REPOSITORY @ WVU

Graduate Theses, Dissertations, and Problem Reports

2010

\section{Long term AMPK activation limits obesity induced muscle atrophy}

Joshua C. Drake

West Virginia University

Follow this and additional works at: https://researchrepository.wvu.edu/etd

\section{Recommended Citation}

Drake, Joshua C., "Long term AMPK activation limits obesity induced muscle atrophy" (2010). Graduate Theses, Dissertations, and Problem Reports. 2992.

https://researchrepository.wvu.edu/etd/2992

This Thesis is protected by copyright and/or related rights. It has been brought to you by the The Research Repository @ WVU with permission from the rights-holder(s). You are free to use this Thesis in any way that is permitted by the copyright and related rights legislation that applies to your use. For other uses you must obtain permission from the rights-holder(s) directly, unless additional rights are indicated by a Creative Commons license in the record and/ or on the work itself. This Thesis has been accepted for inclusion in WVU Graduate Theses, Dissertations, and Problem Reports collection by an authorized administrator of The Research Repository @ WVU. For more information, please contact researchrepository@mail.wvu.edu. 


\title{
Long Term AMPK Activation Limits Obesity Induced Muscle Atrophy
}

\author{
By \\ Joshua C. Drake \\ Thesis submitted to the School of Medicine \\ at West Virginia University \\ in partial fulfillment of the requirements \\ for the degree of \\ Master of Science \\ in \\ Exercise Physiology
}

Approved by

David L. Williamson Ph.D, Committee Chairperson

Gregory M. Dick Ph.D

John M. Hollander Ph. D.

Department of Exercise Physiology

Morgantown, West Virginia

2010

Keywords: Obesity, Atrophy, mTOR, AMPK 


\section{Abstract \\ Long Term AMPK Activation Limits Obesity Induced Muscle Atrophy}

\section{Joshua C. Drake}

The aim of this study was to identify obesity-induced alterations in regulatory mechanisms of skeletal muscle mass and how they would be altered with long term (8 weeks) AMPK-agonist treatment. 8 week old male, lean (L) wild type [body weight $(B W)=26.9 \mathrm{~g}$ ] and ob/ob $(\mathrm{O})[\mathrm{BW}=46.2 \mathrm{~g}$ ] mice were fed an AMP kinase (AMPK) activator, $\beta$-GPA $(F)$, mixed at a $1 \%$ concentration within their food or normal chow as control (C) for 8 weeks. Following an overnight (12 hr) fast, all mice were sacrificed and the gastrocnemius complex was excised for analysis. Muscle mass was lower in the OC mice $(121.08 \pm 9.3 \mathrm{mg})$ versus LC $(158.4 \pm 5.6 \mathrm{mg})$. This corresponded with decreases in raptor associated with mTOR. Following treatment, western analysis of OF muscle lysates displayed increased AMPK and acetyl-CoA carboxylase phosphorylation compared with LC and $\mathrm{OC}$ mice. OC mice displayed higher activation of mammalian Target of Rapamycin (mTOR)-regulated signaling (S6K1, 4E-BP1, and GSK3), which was reciprocally altered after 8 weeks of $\beta$-GPA feeding. These data show that long term (8 week) AMPK-agonist treatment can augment obesity-induced alterations in regulatory mechanisms of skeletal muscle mass through the normalization to lean levels of mTOR signaling. 


\section{DEDICATION}

The author wishes to thank his wife, Carri, and their son, Liam, for their love and support. 


\section{ACKNOWLEDGMENTS}

The author wishes to thank all of the people that helped make this work possible:

Committee Members:

- Dr. David Williamson

- Dr. Gregory Dick

- Dr. John Hollander

Dr. Alway's Lab:

- Dr. Alway

- Dr. Hao

- Janna Jackson

- Yan Wang

Dr. Hollander's Lab:

- Courtney Williamson

- Walt Baseler

- Errine Dabkowski

- Tara Croston

Dr. Dick's Lab

- Shinichi Asano

Dr. Frisbee's Lab:

- Milinda James 


\section{TABLE OF CONTENTS}

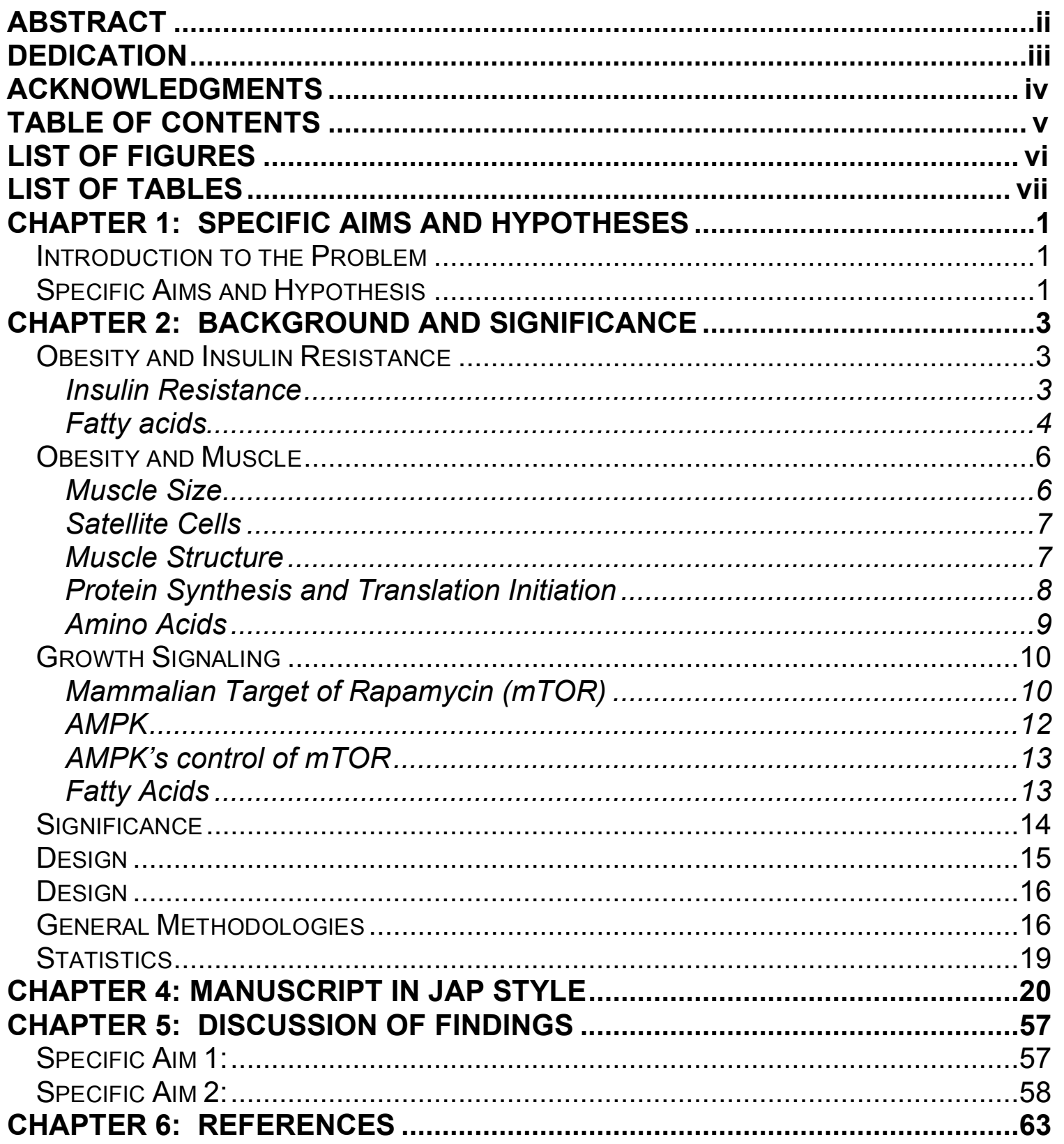




\section{LIST OF FIGURES}

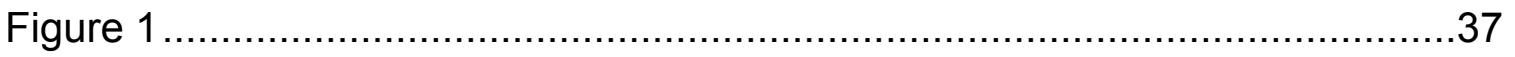

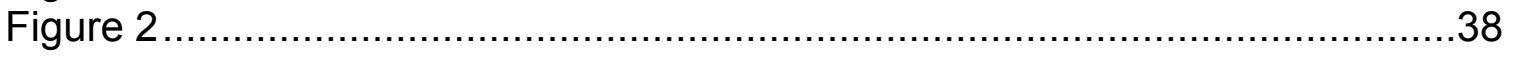

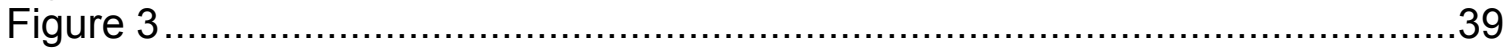

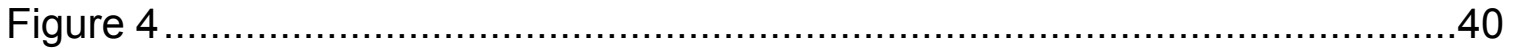

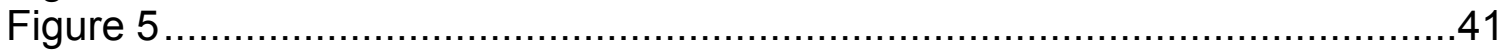

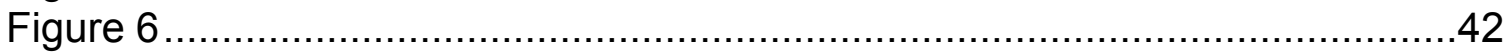

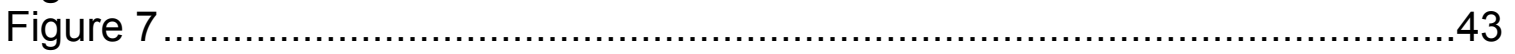

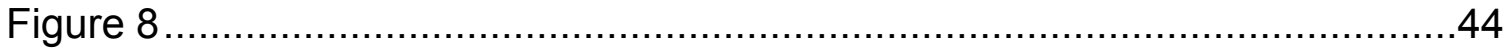

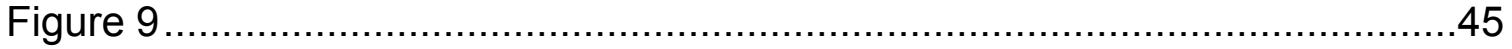

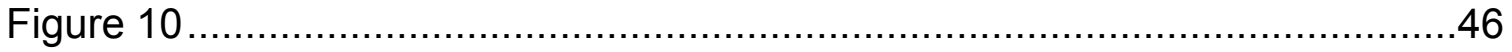

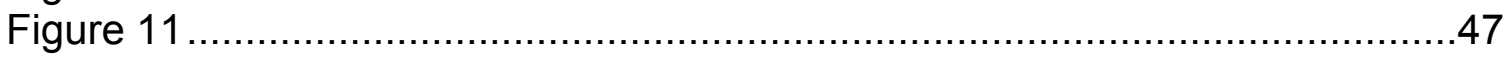

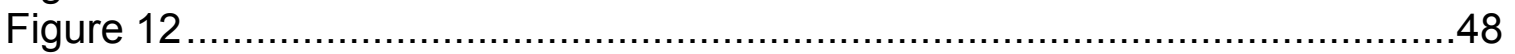

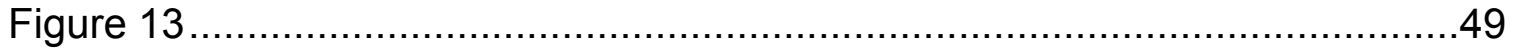

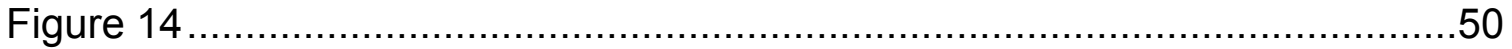

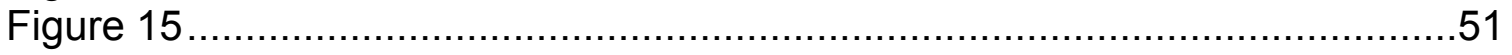




\section{LIST OF TABLES}

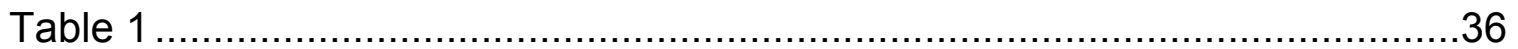


Chapter 1: Specific Aims and Hypotheses

\section{Introduction to the Problem}

Obesity has recently moved to the forefront of health care concerns in the United States. Many of the health problems associated with obesity like lipotoxicity, dyslipidemia, type 2 diabetes and chronic inflammation have significant impacts on skeletal muscle function. These decreases in function impact the activity level, independence, and quality of life of an individual. This decrease in function is due to muscle atrophy induced by obesity (54). Loss in muscle mass is due to an imbalance between the protein synthesis and degradation rates (3). Mammalian Target of Rapamycin (mTOR) increases RNA translation and protein synthesis initiating growth. As growth is an energetically expensive process, mTOR responds in the presence of adequate nutrients $(4,5$, $41,68,84)$. Obesity is a state of excessive nutrients and displays elevated mTOR signaling, however, skeletal muscle atrophy is present $(6,27,38,63,67$, 72). AMP-activated protein kinase (AMPK), a sensor of low energy and malnutrition, inhibits the mTOR pathway and promotes oxidative metabolism. While numerous studies have examined AMPK in relation to metabolic complications during obesity, it remains unclear how therapies activating AMPK and/or repressing highly activated mTOR will improve obesity-induced muscle atrophy. Understanding this dysregulation and how AMPK activation affects growth signaling will provide insights towards new and innovative ways to treat and prevent the problem of obesity, resulting in improved quality of life in these individuals and lower health care costs.

\section{Specific Aims and Hypothesis}

The objectives of this study are to: (1) evaluate the effectiveness of AMPK agonist treatment on skeletal muscle growth and protein formation during obesity; (2) identify the central regulatory pathway that contributes to muscle atrophy induced by obesity. The central hypothesis of this study is that AMPK activation can improve obesity-induced skeletal muscle atrophy by 
augmenting growth signaling. We will test the central hypothesis and accomplish the objectives of this study by pursuing the following specific aims:

1. Determine the role of AMPK activation on skeletal muscle mass and morphology within obese muscle. Our hypothesis is that 8 weeks of $\beta$ GPA (AMPK agonist) feeding will activate AMPK, increasing total muscle mass relative to body weight and tibial length by enhancing accretion of protein in obese skeletal muscle.

2. Determine how obesity alters mTOR-related signaling in skeletal muscle and evaluate the benefit of AMPK activation. Our hypothesis is that activated AMPK will subsequently improve growth related signaling, such as Akt, by reducing the activation of mTOR substrates S6K1 and 4E-BP1 and promote proper ratio of mTOR with raptor and elF4F complex formation in fasted obese skeletal muscle. 
Chapter 2: Background and Significance

Obesity and Insulin Resistance

Obesity has become a major medical concern in most of the developed world, particularly, in the United States. The Center for Disease Control and Prevention $(C D C)$ define obesity as a body mass index $(B M I) \geq 30$. Over the past 20 years the US has seen a significant increase in the amount of the population that fits this criterion. In 2008 , thirty-two states showed a $25 \%$ or greater prevalence of obesity among their populations. Six of those (Alabama, Mississippi, Oklahoma, South Carolina, Tennessee, and West Virginia) showed that $30 \%$ or greater of their population had a BMI of at least $30(2)$.

Insulin Resistance

Insulin resistance is commonly associated with excessive weight gain and/or hyperlipidemia, i.e. obesity (43). Using the homeostasis model assessment index (HOMA) and glucose sensitivity index ( $\mathrm{Si}$ ) on obese and lean subjects showed that the HOMA was 2.3 fold higher in obese compared to the lean and the Si was 2.1 higher in the lean compared to the obese subjects (57). Insulin resistance is also associated with an increase in several pancreatic peptides other than just insulin, such as amylin (an insulin complement that regulates glucose appearance), glucagon (important in carbohydrate metabolism), and gastric inhibitory polypeptide (helps induce insulin secretion) (57).

Glucose uptake into skeletal muscle accounts for approximately $80 \%$ of the total insulin-stimulated glucose disposal (81). Because of this, skeletal muscle is heavily linked to the development of the insulin resistance that leads to type 2 diabetes (39). The primary means by which glucose enters skeletal muscle is by the Glut 4 transport protein (39). In obese men and diabetic rats, Glut 4 has lower expression when compared to lean controls $(21,39)$. Glut 4 expression is also fiber type-dependent. He et al. (28) proposed that a muscle fiber's sensitivity to insulin was dependent on the fiber type with type I being the 
most sensitive, followed by type Ila then Ilb. Using Sprague-Dawley rats, at physiological insulin concentration, red (type I) muscle transports twice as much glucose as white (type II) muscle (39). From basal insulin concentrations to maximum concentration, type II skeletal muscle shows only a $6 x$ increase in glucose transport compared to a 17x increase in type I skeletal muscle fibers (39). Type I fibers also contain 5.2x more Glut4 mRNA as well as total protein when compared to type II fibers (39).

\section{Fatty acids}

Obese human subjects display significant increases in endogenously synthesized long-chain fatty acid species C16:0, C16:1, C18:1 (57). This increase in the fatty acid pool represents the fatty acids circulating in triglycerides or other esterified species. Because of this, obese subjects display higher triglyceride levels when compared to lean cohorts (57). Increases in circulating triglycerides are central in the pathogenesis for their accumulation within skeletal muscle $(47,74)$, known as intramuscular triglycerides (IMTG). Both in vitro and in vivo exposure of skeletal muscle to increased lipids, (ex. high fat diet or lipid infusion) results in an accumulation of IMTG $(21,28,35,43,94)$. This corresponds with the increase in IMTG that is seen within the skeletal muscle of obese and type 2 diabetic subjects when compared to lean controls $(21,23,43$, 88, 94). There is a fiber type-specific accumulation that occurs in association with obesity and type 2 diabetes in that IMTG are further elevated in the type I fibers (23). For example, in soleus muscles (comprised primarily of type I fibers) of obese adolescent males showed an increase in IMTG (74). An increase in IMTG depends on several factors: the availability and efficiency of fatty acid uptake, the rate of fatty acid oxidation, and the rate of synthesis and hydrolysis of triacylglycerides (94).

A large proportion of fatty acid oxidation, referred to as $\beta$-oxidation, occurs within the skeletal muscle or more specifically within the mitochondria (88). Regulation of mitochondrial function is believed to be through peroxisome 
proliferators-activated receptor gamma coactivator 1-alpha (PGC-1 $\alpha$ ) (11). Cultured myotubes from type 2 diabetic patients display mitochondrial dysfunction which is believed to be caused by disturbances that occur downstream of $\beta$-oxidation (94). Thus, during increases in fatty acid influx or $\beta$ oxidation there is corresponding increase in production and release of acid soluble metabolites that result in the increases in IMTG seen in obesity and type 2 diabetes (94). When these myotubes from type 2 diabetic patients are exposed to elevated fatty acids, PGC-1 $\alpha$ (a key factor in $\beta$-oxidation) gene expression is increased but the response is blunted (94). PGC-1 $\alpha$ coactivator peroxisome proliferators-activated receptor (PPAR $\gamma$ ) and mitochondrial marker cytochrome c oxidase IV (COXIV) are significantly reduced in the muscles of raptor (a component of mTOR essential for proper muscular growth) knock out mice linking its functions to that of muscle growth (4).

Lipolysis is the catabolic reaction that breaks down one molecule of TAG into three fatty acid molecules (56). When dysregulation of lipolysis of IMTG is present there is an increase in the amount of diacylglycerides (DAG). Moro et al (56) compared the hydrolysis of TAG and DAG and found an imbalance that resulted in a higher rate of TAG hydrolysis compared to DAG hydrolysis, which caused DAG to accumulate. The dysregulation of lipolysis just mentioned is also responsible for the creation of new ceramides within the skeletal muscle (56). Ceramides and DAG are both associated with the lipotoxicity that is found in obese and type 2 diabetic populations $(56,97)$, although DAG is believed to be the most influential of the two. Ceramides have been shown to not change following a $5 \mathrm{hr}$ lipid infusion (97), however, this could be due to the period of infusion not being long enough. Therefore, it is not IMTG themselves that contribute to insulin resistance but rather impairments in the way they are broken down.

A high fat diet increases IMTG but it also decreases insulin stimulated skeletal muscle glucose uptake (58). The dysregulation of lipolysis through 
increases in circulating free fatty acids and the subsequent accumulation of IMTG is integral in the pathogenesis of insulin resistance by inhibiting glucose transport $(47,68)$. This manifests as a decrease in glucose oxidation and the synthesis of glycogen within skeletal muscle (68). Intramuscular glucose-6phosphate concentration, whose release is insulin dependent and vital in glycolysis within the muscle, is lowered below baseline values in nine healthy human subjects following lipid infusion (68), further suggesting that fatty acids play an inhibitory role in glucose transport.

Further investigation into the signaling behind insulin resistance shows that increases in plasma fatty acids inhibit insulin activation of insulin receptor substrate 1 (IRS-1) associated PI3-kinase at the level of IRS-1 (97). A 30\% reduction in IRS-1 tyrosine phosphorylation and a 50\% reduction in IRS-1 associated PI3-kinase activity is observed in rats following $5 \mathrm{hrs}$ of lipid infusion (97). The reduction in insulin activation of IRS-1 associated PI3-kinase activity coincides with activation of the enzyme Protein Kinase $C$ that is believed to be responsible for the inhibition of IRS-1. PKC- $\theta$ needs DAG for activation, which is already elevated during obesity and type 2 diabetes $(56,97)$ so the role of PKC- $\theta$ in the inhibition of IRS-1 associated PI3-kinase activity is likely.

\section{Obesity and Muscle}

\section{Muscle Size}

In obesity the mass of the muscle in proportion with body size is reduced, significantly impacting the function of skeletal muscle. When comparing 74 obese human subjects (BMI $\geq 30 \mathrm{~kg} / \mathrm{m} 2$ ) to 67 lean subjects (BMI $<25 \mathrm{~kg} / \mathrm{m} 2$ ), the obese subjects had twice as much total fat mass as the lean controls, but only a $17 \%$ increase in lean mass (57). This corresponded to $60 \%$ of the obese subjects' body weight being made up of muscle compared to $71 \%$ in the lean controls (57). This trend is also visible in mice and is specific to the muscle (38). In ob/ob mice the sternomastoid, extensor digitorum longus (EDL), and soleus muscles are $30 \%, 21 \%$, and $13 \%$ smaller, respectively, when compared to lean 
controls (38). This corresponded to a muscle mass-to-body mass ratio of $-62 \%$ for the sternomastoid, $-56 \%$ for the EDL, and $-52 \%$ for the soleus compared to lean controls. These smaller muscle sizes in obese mice were also associated with smaller fiber size by examining the cross sectional areas, except in the soleus where the cross sectional area was similar between ob/ob and lean mice (38).

\section{Satellite Cells}

During normal turnover in skeletal muscle, myofiber nuclei are lost. The maintenance and replacement of these nuclei is the role of satellite cells. Satellite cells are normally found between the basal lamina and the sarcolemma of the myofibrils. Hypertrophy of skeletal muscle depends on proper function of these satellite cells (62). Obese Zucker rats, an insulin resistant obese model, show a decrease in the amount of myonuclei compared to lean cohorts, evidenced by BrdU staining on plantaris and soleus muscle (62). Similar findings have been seen in the ob/ob mouse. Myofibers in 3-week-old ob/ob mice had less satellite cell proliferative activity than did lean controls (63).

\section{Muscle Structure}

Skeletal muscle is made up of different types of myofibers. The two main types are the slow-twitch oxidative fiber, Type I, and the fast-twitch glycolytic fibers, Type Ila, IIx, Ilb and IIc $(7,14,61)$. Each fiber type has different metabolic properties. Type I fibers, for example, have been shown to contain a high amount of intramuscular lipids, not seen in type II fibers $(20,28,36,42)$. Type I fibers, which use primarily aerobic metabolism, are better equipped to use lipids as fuel. It has been shown that the amount of weight loss and reduction in BMI following gastric bypass surgery in morbidly obese subjects was related with the amount of type I fibers each subject had (82).

It has been shown in rats, mice, and humans that there is a significant decrease in the amount of type I fibers associated with obesity $(27,29,31,36$, 
$38,83,88)$. Likewise, there is a significant increase in type II fibers with obesity $(36,38,83)$, particularly type Ilb fibers $(36,83)$. Along with this fiber type shift there has been found to be an increase in the amount of hybrid fibers in the sternomastoid, EDL, and the soleus in ob/ob mice compared to lean cohorts (38). This shift corresponds with the increase in functional demand on the postural muscles that are now being required to support a larger body mass, locomotor muscles that are overcoming greater inertia in order to move, and an increase in the effort behind ventilation (38).

\section{Protein Synthesis and Translation Initiation}

Obesity by itself can cause complications with protein synthesis. Mice that were made obese by goldthioglucose injection showed less adaptive growth following an exercise regime (3). When compared to lean controls, these obese mice showed only a $2 x$ increase in protein turnover whereas lean mice show a $3 x$ increase (3). Protein content is also lower in the muscles of the obese mice compared to lean cohorts (3). There is data suggesting that altered protein synthesis in the obese is slower in slow (type I) muscle more so than fast (type II) muscle fibers. Protein turnover has been shown to be slowest and total RNA content lower in type I fibers of the vastus lateralis fibers of dogs, mice, rats, and fowl (75).

Muscle growth is dependent upon the synthesis of proteins through the initiation of polypeptide chains. Protein synthesis within skeletal muscle is controlled by hormonal and nutritional factors as well as the body's supply of amino acids, insulin and other initiation factors, RNA, and met-tRNA (64). Insulin does not necessarily stimulate protein synthesis but rather facilitates synthesis by stimulating downstream machinery (79). For example, for the initiation of peptide-chains to take place within eukaryotic cells there must be an mRNA dependent binding of the $40 \mathrm{~S}$ and $60 \mathrm{~S}$ ribosomal subunits creating an $80 \mathrm{~S}$ monomer (64). The binding of mRNA to the $40 \mathrm{~S}$ ribosomal subunit involves the binding of elF-4E (eukaryotic initiation factor - 4E) to the m7GTP cap at the 
5'end of the mRNA. The newly formed elF-4E - mRNA complex binds to another initiation factor, elF-4G, which contains binding sites for the other initiation factors, elF-4A and elF-3. This complex then binds to the $40 \mathrm{~S}$ ribosomal subunit (78). Phosphorylation of 4E-BP1 is caused by insulin and IGF-1 (79). 4E-BP1 also regulates $40 \mathrm{~S}$ ribosome binding to $\mathrm{mRNA}$, though indirectly, by increasing the availability of elF-4E (78). When elF-4E is bound to $4 \mathrm{E}-\mathrm{BP} 1$ it can bind to mRNA through the m7GTP cap but not to elF-4G. But when 4E-BP1 is phosphorylated it releases elF-4E allowing it to bind with elF-4G and subsequently to the $40 \mathrm{~S}$ ribosomal subunit (78).

Impaired insulin and IGF-1 action, like in obesity and diabetes, leads to atrophy of skeletal muscle due to its inability to synthesize proteins $(37,57)$. In the $\mathrm{db} / \mathrm{db}$ diabetic mouse model, there is a $48 \%$ decrease in protein synthesis when compared to lean controls (72). The accompanying decrease in RNA negatively affects translational efficiency not allowing the formation of new peptide chains (64). RNA concentrations in gastrocnemius muscles of male Sprague-Dawley rats were $13 \%$ lower after just two days in a simulated diabetic state (25). Since approximately $80 \%$ of RNA is rRNA, any decreases in RNA will blunt protein synthesis (25).

\section{Amino Acids}

Part of the action of insulin on protein synthesis is its effects on stimulating the incorporation of amino acids into proteins (78). Increases in the amounts of circulating amino acids are observed in obesity (57). Branched chain amino acids have been shown to affect carbohydrate metabolism by decreasing the glucose used within skeletal muscle (60). In obese humans, eight amino acids have been shown to be significantly increased (alanine, valine, leucine/isoleucine, phenylalanine, tyrosine, glutamate/glutamine, aspartate/asparagines, and arginine) compared to lean cohorts (57). This could cause a build up in these amino acids because they compete for transport with the large neutral amino acid transporter, LAT1, resulting in the reduced 
production of neurotransmitters (i.e. serotonin) and catecholamines within the central nervous system (57). Since IGF-1 is decreased in obesity, combined with overnutrition, the larger amounts of circulating amino acids will be diverted into catabolic pathways instead of being used for protein synthesis. For example, glutamate increases in $\alpha$-ketoacids, C5, and C3 acylcarnitines. C5 acylcarnitines are comprised of subunits that lead to mitochondrial isoleucine and leucine catabolism (57). High glutamate could also increase transamination of pyruvate to alanine (both found to be increased in obesity), which could lead to glucose intolerance in obesity (57).

\section{Growth Signaling}

Mammalian Target of Rapamycin (mTOR)

Rapamycin is used in clinical applications, such as organ transplants and cancer treatment, because of its immunosuppressive action that negatively affects proliferation. The molecular target of rapamycin is a Ser/Thr kinase called mTOR in mammals (86). mTOR is a part of the phosphatidyl-inositol 3 kinase (PI3K) family of enzymes (67). mTOR is associated with sensing nutrient availability, adjustment of insulin action in vivo, increases in muscle mass via an increase in RNA translation and protein synthesis, the balance of ATP production, and regulating mitochondrial function $(4,5,44,71,92)$. mTOR is comprised of two separate multiprotein complexes, mTOR Complex 1 (TORC1) and mTOR Complex 2 (TORC2) $(34,69)$. TORC1 consists of the regulatory protein of mTOR, raptor, which is rapamycin-sensitive $(4,41)$. Raptor interacts with IRS-1 to regulate the phosphorylation of IRS-1 at Ser-636/639 by mTOR (89). TORC1 controls the phosphorylation of downstream targets 4E-BP1 and ribosomal protein S6 kinase-1 (S6K1) (16). When mTOR phosphorylates 4E$\mathrm{BP} 1$, elF-4E is free to bind with other initiation factors and the 40S ribosomal subunit, allowing translation initiation to occur. S6K1 activation causes feedback inhibition of the insulin/IGF1 pathway by decreasing the levels and phosphorylation of IRS-1 $(26,90)$. However, this effect on IRS-1 phosphorylation is not direct. This is done through another negative feedback regulation of PI3- 
kinase/Akt signaling by phosphorylating rapamycin-sensitive residues such as Ser307 (89). Another protein in TORC1 is $\mathrm{mLST8}$, which interacts directly with mTOR and positively regulates its ability to phosphorylate S6K1 (89).

In muscle cells glucose uptake is controlled through activation of the PI3kinase/Akt pathway, which is stimulated by insulin (59). When TORC1 is activated for prolonged periods of time, as is the case in nutrient excess, insulin resistance results due to decreased signal transduction of insulin the level of IRS-1 (54, 67, 85). Consequently, ribosomes released following peptide-chain termination accumulate as $80 \mathrm{~S}$ monomers, not as $40 \mathrm{~S}$ and $60 \mathrm{~S}$ subunits (37). This has detrimental effects on translation initiation. Insulin resistance associated with increased TORC1 is evidenced in the ob/ob mouse, which has constantly activated TORC1 associated with increases in basal PKB/Akt activity (54).

Raptor knock out mice (RAmKO) show significant decreases in S6K1 and 4E-BP1 phosphorylation and display progressive muscular dystrophy (4). Glycogen content is increased in the EDL, soleus, and gastrocnemius muscles of these animals (4). EDL and soleus muscles in RAmKO mice also display significant decreases in oxidative enzymes, intermyofibrillar mitochondria, and glucose uptake from the blood (4). This provides further evidence of the role of the complex in controlling muscle mass, oxidative metabolism, and insulin action.

TORC2 consists of Rictor, which is the rapamycin-insensitive component of mTOR (4). TORC2 controls the phosphorylation of PKB/Akt at Ser473 (70). PKB/Akt acts as a feedback regulator of TORC1 activation (6) and is acted on by S6K1 to regulate IRS-1 phosphorylation through negative feedback (89). PKB/Akt increases TORC1 by phosphorylating TSC 1 and 2 (54). This enhances GTP loading to Rheb, an mTOR interacting protein that is essential for mTOR activity (54). In order for phosphorylation of Akt at Ser 473 to take place the rictor interacting protein $\mathrm{mSin} 1$ is required (89). A downstream target of PKB/Akt is glycogen synthase kinase $3 \alpha / \beta$ (GSK3 $\alpha / \beta)$. The $\beta$ isoform of GSK3 has been 
shown to be the major enzyme that inhibits glycogen synthase $(33,52)$. When phosphorylated by Akt, GSK3 $\beta$ is inhibited, increasing glycogen synthase activity (52).

The rictor knock out mouse (RImKO) appears normal and does not die prematurely like RAmKO mice (4). There is no change in the structural makeup of the EDL and Soleus muscles that is responsible for the absence of muscular dystrophy (4). Interestingly, there is a slight decrease in the amount of raptor in the RImKO mice (4). PKB/Akt on Ser 473 is still phosphorylated, meaning that mTORC2 is not required for its phosphorylation (4) but apparently it plays a role in the degree of raptor expression.

\section{$A M P K$}

AMPK operates in response to stress as a cellular fuel sensor particularly as a result of the AMP:ATP ratio $(12,24)$. AMPK is a ubiquitous Ser/Thr kinase heterotrimer made up of a catalytic $\alpha$ subunit as well as $\beta$ and $\gamma$ regulatory components that complete the complex $(35,48)$. The most common causes of AMPK activation are hypoglycemia, exercise, and fasting (35). When activated, it initiates the production of ATP while inhibiting pathways that consume it (48). In skeletal muscle, AMPK regulates glucose metabolism and gluconeogenesis (66). It also controls fatty acid oxidation by phosphorylating acetyl-CoA carboxylase 2 (ACC2) (66). Situations where lipid metabolism is impaired, as in obesity, could be a result of a dysregulation in the fuel sensing ability of AMPK (35). If fatty acids cannot be oxidized within the mitochondria they will be synthesized into DAG, ceramides, and TG within the cytosol causing inhibition of the insulin pathway decreasing glucose uptake (35). 3-guanidinopropionic acid $(\beta-G P A)$ is a known AMPK activator by competing against phosphocreatine and not allowing it to enter into the muscle and subsequently lowing ATP levels (18, $19,73)$. $\beta$-GPA has been shown to induce hypoglycemia in non-diabetic rabbits

(1). Its effects on reducing glucose and insulin levels as well as increasing insulin sensitivity have been seen in ob/ob mice (53). 5'-aminoimidazole-4- 
carboxamide-1- $\beta$-D-ribofuranoside (AICAR) is another known AMPK activator $(10,12,67)$. AICAR acts as an intermediate in the generation of inosine monophosphate (IMP), an AMPK agonist, thus increasing activity of AMPK (10, 12, 67). Exercise also affects AMPK by depleting ATP and increasing amounts of AMP. This change in the AMP:ATP ratio increases AMPK activity.

\section{AMPK's control of mTOR}

AMPK controls translation and growth via an mTOR dependent mechanism. Increases in AMP activate AMPK by phosphorylating the Thr 172 residue on the catalytic $\alpha$ subunit (35). AMPK in turn causes the phosphorylation and subsequent inactivation of acetyl-CoA carboxylase (ACC), the rate-limiting enzyme in fatty acid oxidation (83). ACC has two isoforms, ACC1 and ACC2, with ACC2 being the predominant isoform within skeletal muscle. AMPK phosphorylates ACC1 on Ser 79 and ACC2 on the equivalent Ser 221 repressing the mTOR pathway $(23,83)$. This decreases fatty acid production as well as upregulates fatty acid oxidation and mitochondrial biogenesis by increasing citrate synthase and succinate dehydrogenase $(23,35,66,67,77)$.

AMPK phosphorylates the tuberous sclerosis complex 2 gene product, Tuberin or TSC2 (92). TSC2, whose function is inhibited upstream by Akt, functions as a GTPase-activating protein (GAP) to the Rheb G protein, an upstream target of mTOR (13). Rheb is then converted to its inactive GDP form that decreases mTOR activity (13). Therefore, AMPK also acts indirectly to inhibit mTOR signaling through TSC2.

\section{Fatty Acids}

Chronic exposure to lipids increases mTORC 1 and 2 formation (67). Increases in mTORC1 were indicated by increased activation of S6K1 at Thr 389 (67). This increased the serine phosphorylation of IRS-1 (67). mTORC2 formation was coupled with increases in Akt at Ser 473 (67). Increases in fatty acids have also been associated with suppressed AMPK signaling (76). 


\section{Significance}

Considering the rising prevalence of obesity among the population of this country, understanding the effects that obesity has on skeletal muscle mass will be crucial for combating this problem. Because of the role skeletal muscle plays in substrate utilization, basal metabolic rate, functionality, and personal independence, any detriments in size and function of the muscle has significant impacts on both quality of life and the financial burden of health care. As our obese population grows older, there will be factors contributing that are detrimental to skeletal muscle. Having an understanding of skeletal muscle mass in the role of obesity alone plays will improve care in individuals. Findings from this study will point towards new ways to treat and prevent the problem of obesity, thus improving the quality of life in these individuals. 
Chapter 3: Methods

\section{Aim \#1: Determine the role of AMPK activation on skeletal muscle mass and morphology within obese muscle. \\ Design}

The experimental groups consisted of 8 C57BL/6 (lean) mice and 8 ob/ob mice fed either a 1\% $\beta$-GPA containing diet, or 8 lean and ob/ob mice fed normal chow. Ob/ob mice are a rodent model of obesity and hyperlipidemia. These mice spontaneously develop a mutation of the leptin gene and subsequently develop high circulating levels of triglycerides, total cholesterol, and low density lipoproteins $(15,32)$. The ob/ob mouse also displays characteristics of type 2 diabetes in that hyperinsulinemia, hyperglycemia, insulin resistance, hyperaminoacidemia, and intolerance to glucose are all present $(9,15,49-51)$. Few studies have examined skeletal muscle growth regulation in these animals or how to attenuate their muscle loss. The data show lower activation of the insulin stimulated PI 3-kinase/Akt growth pathway and that mTOR signaling is highly active in these animals $(54,98)$. This makes them a good experimental model to gain insight into the intricacies of how these pathways control muscular growth during obesity but also to discover an efficient means by which to treat these pathologies.

Feeding with $1 \% \beta$-GPA is being used as a means to increase AMPK activation. This quantity of $\beta$-GPA was chosen based on the viability and response of the animals in previous experiments using the same diet (17-19, 73). Body weight and food intake were recorded twice a week for the duration of the 8-week feeding. The experimental period is ample time to observe changes in skeletal muscle mass relative to body weight and tibial length $(75,87)$. The average weight of the mice in each cage as well as food intake was calculated each week. Following a $12 \mathrm{hr}$ fast, muscle was collected while the animal was anesthetized. Gastrocnemius complexes were weighed then immediately frozen in liquid nitrogen. Tibial lengths were measured as another means to normalize 
muscle growth. We measured the ATP in muscle and examined AMPK activation as validation of the treatment.

\section{Aim \#2: Determine how obesity alters mTOR-related signaling in skeletal muscle and evaluate the benefit of AMPK activation. \\ Design}

The experimental groups consisted of 8 C57BL/6 (lean) mice, 8 ob/ob mice fed a $1 \% \beta$-GPA containing diet, and 8 lean and ob/ob mice fed normal chow. 1\% $\beta$-GPA was used as a means to increase AMPK activation and repress mTOR signaling. This quantity of $\beta$-GPA is based on the viability and response of animals in previous experiments using the same diet $(17-19,73)$. The goal was to identify the regulatory pathway through which AMPK activation attenuates obesity-induced muscle atrophy. The experimental period was ample time to observe changes in skeletal muscle mass relative to body weight and tibial length. Body weight and food intake were measured $2 x$ week throughout the feeding period. After the proposed period, muscle samples were collected while the animal is under anesthesia. The gastrocnemius complex was analyzed by immunoprecipitation and Western Blot for mTOR and mTOR-related activation and association.

\section{General Methodologies}

Animals - Lean and ob/ob (Catalog \#000632) male mice from Jackson Laboratories in Bar Harbor, ME were used for the proposed experiments. All animals were maintained on a 12:12, light:dark cycle and controls were fed standard chow (Harlan; \#2018) while the experimental groups are fed $\beta$-GPA (Sigma-Aldrich; \#G 6878) mixed with standard chow (Harlan; \#2018). The experimental diet was prepared by Harlan. The experimental groups consisted of 8 C57BL/6 (lean) mice fed $\beta$-GPA, 8 ob/ob mice fed $\beta$-GPA, and 8 lean and ob/ob mice fed normal chow. Food and water was available ad libitum. After the proposed time and following an overnight fast, samples were collected while the animal was anesthetized by $4 \%$ isoflurane. Body weight was measured while the 
animal was anesthetized. Gastrocnemius complexes were removed and weighed then immediately frozen in liquid nitrogen for later analysis. The right tibia was removed and immediately placed in a $-20^{\circ} \mathrm{C}$ freezer until the length could be measured.

$\beta$-GPA - 3-guanidinopropionic acid was mixed with normal chow from Harlan to make a $1 \% \beta$-GPA mixture $(17-19,73)$. Body weight was measured every $3^{\text {rd }}$ day ( $2 x$ week). Food intake was measured at those times to track food consumption. The average weight and food intake, per mouse of each cage was calculated at the end of each week to track body weight gain and food consumption.

Muscle Size - The gastrocnemius complex (soleus, plantaris, and the two heads of the gastroc) was surgically dissected tendon-to-tendon and any fat around the tissue was removed before the muscle was weighed. Because of the likelihood that body mass change is accompanied by a change in muscle mass, muscle mass was normalized to body weight, skeletal muscle protein concentration, and tibia length.

ATP Determination -Invitrogen Detection Technologies ATP Determination Kit (A22066) was used. This is a bioluminescence assay for quantitative determination of ATP with recombinant firefly luciferase and its substrate Dluciferin. Amount of ATP was calculated in the experimental samples from a provided standard curve.

Homogenizing of Muscle - Muscle tissue was homogenized in 10x homogenizing buffer. Homogenizing buffer consisted of $10 \mu \mathrm{l} / \mathrm{ml}$ protease inhibitor, $1 \mu \mathrm{l} / \mathrm{ml}$ DTT, $5 \mu \mathrm{l} / \mathrm{ml}$ Benzamidine, $2.5 \mu \mathrm{l} / \mathrm{ml}$ Sodium Vanadate, and the rest was made up of CHAPS buffer. A $50 \mu \mathrm{l}$ aliquot of the total homogenate was placed in a separate tube with $50 \mu \mathrm{l}$ of sample buffer for totally lysate analysis. The remaining homogenates were spun at $1000 \times \mathrm{x}$ for $10 \mathrm{~min} @ 4{ }^{\circ} \mathrm{C}$. The 
supernatant was taken and placed in separate tubes and the remaining pellet will be discarded. An aliquot of $10 \mu \mathrm{l}$ was taken of the samples for a protein assay while the rest was stored in an $-80^{\circ} \mathrm{C}$ freezer.

Protein Determination - Bovine serum albumin was used to determine protein concentration of the muscle samples using the Coommassie Stain Assay (Thermo Scientific). The plate was run through the plate reader $(595 \mathrm{~nm})$ to calculate protein concentration. A workable dilution was calculated for each sample that was used in subsequent Western Blot analysis.

Immunoprecipitation - The sample was processed in CHAPS buffer and $500 \mu \mathrm{g}$ of $1000 x g$ supernatant was combined with elF-4E or mTOR antibody and mixed overnight. Immune complexes were isolated with a goat anti-rabbit or -mouse BioMag IgG beads (Qaigen), using a magnetic stand. Precipitates were eluted in SDS sample buffer, boiled, pelleted by magnet, collected, and subjected to standard Western analysis for elF-4E, elF-4G, and 4E-BP1 (elF-4E IPs only) or mTOR and raptor (mTOR IPs only). mTOR's association with raptor was analyzed from mTOR immunoprecipitates, and elF-4E and 4E-BP1 associated with elF-4E was examined in elF-4E immunoprecipitates.

Western Analysis - Degree of activation of AMPK, mTOR and their substrates raptor, S6K1 (total and phospho), 4E-BP1 (total and phospho), rpS6, eEF-2, GSK3- $\alpha / \beta$, p-Akt (Ser 473 and Thr 308), total Akt, and ACC were analyzed by Western analysis from skeletal muscle homogenates. Results were normalized to $\beta$-Tubulin. TOR, raptor, S6K1 (total/phospho), GSK3 $\alpha / \beta$, and ACC were run on a $7 \%$ gel. BP1 (total/phospho), eEF-2, and p-Akt (Ser473/Thr 308), and total Akt were run on a $4-12 \%$ gel. AMPK (phospho), PGC- $1 \alpha$, COXIV, $\beta$-Tubulin, and rpS6 (phospho) were run on a 12\% gel. Equal protein was resolved by SDSPAGE (NUPAGE; Invitrogen). A kaleidoscope marker was used to visually determine protein placement based on weight $(\mathrm{kDa})$. Gels ran for $\sim 90$ minutes at $125 \mathrm{~V}$ in cold room until samples have run the length of the gel. They were 
transferred to PVDF membrane for $75 \mathrm{~min}$ at $30 \mathrm{~V}$. The resulting membranes were blocked in $5 \%$ milk ( 5 grams dehydrated milk/100 ml TBST) for $60 \mathrm{~min}$ at room temperature. Membranes were rinsed $4 \times 10$ minutes with 1x TBST and then incubated with the appropriate primary antibody diluted in 1x TBST overnight in cold room. The next day membranes were rinsed $3 \times 5 \mathrm{~min}$ with $1 \times$ TBST then rocked in their respective HRP-conjugated-secondary antibodies diluted in $5 \%$ milk in TBST. All primary and secondary antibodies were purchased through Cell Signaling Technology Inc. Immunoblots were visualized via ECL or ECLAdvanced and captured by a camera-integrated system (SynGene). Concentration of protein expression was assessed by ImageJ software. Results will then be compared to percent of the control.

\section{Statistics}

All data are expressed as mean \pm standard error of the mean. Comparisons are made to the lean controls, using a one- or two-way (body weight and food intake only) ANOVA analysis (Prism v3.0 software; GraphPad Software). The significance level is $P<0.05$. 


\section{Chapter 4: Manuscript in JAP style}

\section{Abstract}

The aim of this study was to identify obesity-induced alterations in regulatory mechanisms of skeletal muscle mass and how they would be altered with long term (8 weeks) AMPK-agonist treatment. 8 week old male, lean (L) wild type [body weight $(B W)=26.9 \mathrm{~g}$ ] and ob/ob $(\mathrm{O})[B W=46.2 \mathrm{~g}]$ mice were fed an AMP kinase (AMPK) activator, $\beta$-GPA (F), mixed at a $1 \%$ concentration within their food or normal chow as control (C) for 8 weeks. Following an overnight (12 hr) fast, all mice were sacrificed and the gastrocnemius complex was excised for analysis. Muscle mass was lower in the OC mice $(121.08 \pm 9.3 \mathrm{mg})$ versus LC $(158.4 \pm 5.6 \mathrm{mg})$. This corresponded with decreases in raptor associated with mTOR. Following treatment, western analysis of OF muscle lysates displayed increased AMPK and acetyl-CoA carboxylase phosphorylation compared with LC and $\mathrm{OC}$ mice. OC mice displayed higher activation of mammalian Target of Rapamycin (mTOR)-regulated signaling (S6K1, 4E-BP1, and GSK3), which was reciprocally altered after 8 weeks of $\beta$-GPA feeding. These data show that long term (8 week) AMPK-agonist treatment can augment obesity-induced alterations in regulatory mechanisms of skeletal muscle mass through the normalization to lean levels of mTOR signaling. 


\section{Introduction}

Many of the health problems associated with obesity like lipotoxicity, dyslipidemia, type 2 diabetes and chronic inflammation have significant impacts on skeletal muscle function. This decrease in function is due to muscle atrophy as seen in both humans and animals $(38,39,54,57)$. Obese humans have been shown to have as much as twice the amount of fat mass as their lean counterparts but only $17 \%$ more lean mass (58). This corresponds to only $60 \%$ of the body weight in obese subjects coming from skeletal muscle compared to $71 \%$ in lean counterparts (58).

Loss in muscle mass is caused by an imbalance between the protein synthesis and degradation rates (3). Synthesis of protein relies upon ribosomal mRNA translation that is controlled by the molecular target of rapamycin in mammals, or mTOR $(5,92)$. Acute increases in mTOR result in muscle hypertrophy and growth but chronically elevated mTOR signaling, as seen in obese muscle, may negatively impact growth $(40,54,90)$.

mTOR is comprised of two separate multi-protein complexes, mTOR complex 1 and 2 , that contain the regulatory proteins raptor and rictor, respectively $(4,35,42,70)$. Raptor phosphorylates the eukaryotic initiation factor (elF) 4E binding protein-1 (4E-BP1) and ribosomal protein S6 Kinase-1 (S6K1) (8). In its unphosphorylated state, 4E-BP1 binds to elF-4E, a key initiation factor in translation, which keeps other initiation factors from binding. Under normal conditions $4 \mathrm{E}-\mathrm{BP} 1$ is phosphorylated by raptor, which then releases elF-4E, allowing it to bind to elF-4G and MAP kinase-interacting kinase to form the elF$4 \mathrm{~F}$ complex $(78,79)$. The elF-4F complex then binds with the mRNA and $40 \mathrm{~S}$ ribosomal subunit so that together with a $60 \mathrm{~S}$ subunit a functional $80 \mathrm{~S}$ monosome can form (78). S6K1 phosphorylation recruits other proteins involved in the translation initiation process such as elF-4B, ribosomal protein S6 (rpS6) and eukaryotic elongation factor 2 kinase (eEF-2) $(16,65)$. 
mTOR can be regulated by a ubiquitous Ser/Thr kinase heterotrimer, 5' AMP-activated protein kinase (AMPK) $(36,53)$. Increases in AMP, activates AMPK by phosphorylating the Thr 172 residue on the catalytic $\alpha$ subunit initiating ATP production and inhibiting pathways that consume it $(36,53)$. AMPK activation causes the phosphorylation and subsequent inactivation of acetyl-CoA carboxylase (ACC), the rate-limiting enzyme in fatty acid oxidation (89). The two isoforms of ACC are phosphorylated by AMPK on Ser 79 (ACC1) and Ser 221 (ACC2) repressing the mTOR pathway $(23,89)$. This decreases fatty acid production as well as up-regulates fatty acid oxidation and mitochondrial biogenesis by increasing citrate synthase and succinate dehydrogenase $(23,36$, 67, 68). AMPK also indirectly regulates mTOR by phosphorylating tuberous sclerosis complex 2 (TSC2) (94). TSC2 functions as a GTPase-activating protein (GAP) to the Rheb G protein, an upstream target of mTOR (13). Rheb is then converted to its inactive GDP form, decreasing mTOR activity (13).

A state of nutrient excess, i.e. obesity, results in chronically elevated mTORC1 and 2 levels and ultimately insulin resistance $(55,68)$. In ob/ob mice, a model of obesity and insulin resistance, it has been shown that there is an accompanied decrease in AMPK signaling (79). However, It is unclear how obese skeletal muscle can display reductions in mass while having excessive nutrients available and increased mTOR signaling. AMPK's control of mTOR and the evidence that it is reduced in obesity make it a desirable target in which to treat altered mTOR signaling in obese skeletal muscle $(13,23,83,96)$. Therefore, our goal in this study is to evaluate the effectiveness of long-term AMPK agonist treatment on skeletal muscle mass during obesity. Our hypothesis is that long-term ( 8 week) treatment with the AMPK agonist, $\beta$-GPA, will normalize obesity-induced increases in mTOR and mTOR-related signaling to lean levels, promoting proper growth of obese skeletal muscle. 


\section{Materials and Methods}

Materials - $\beta$-GPA (3-guanidinopropionic acid) was purchased from SigmaAldrich (\#G6878) and mixed with normal chow from Harlan (\#2018) to make a $1 \% \beta$-GPA mixture $(17-19,73)$. ATP Determination Kit (A22066) was purchased from Invitrogen Detection Technologies. All antibodies were purchased from Cell Signaling Technology. Anti-mouse horseradish peroxidase-conjugated IgG were purchased from Cell Signaling Technology. Biomag beads were purchased from Qaigen.

Animals - Lean and ob/ob (\#000632) male mice from Jackson Laboratories in Bar Harbor, ME were used for the proposed experiments. All animals were maintained on a 12:12, light:dark cycle and controls were fed standard chow (Harlan; \#2018) while the experimental groups are fed $\beta$-GPA (Sigma-Aldrich; \#G 6878) mixed with standard chow (Harlan; \#2018). The experimental diet was prepared by Harlan. The experimental groups consisted of 8 C57BL/6 (lean) mice fed $\beta$-GPA, 8 ob/ob mice fed $\beta$-GPA, and 8 lean and ob/ob mice fed normal chow. Food and water were available ad libitum. After the proposed time and following an overnight fast, samples were collected while the animal was anesthetized by $4 \%$ isoflurane. Body weight was measured while the animal was anesthetized. Gastrocnemius complexes were removed and weighted then immediately frozen in liquid nitrogen for later analysis. The right tibia was removed and immediately placed in a $-20{ }^{\circ} \mathrm{C}$ freezer until the length could be measured.

B-GPA - 3-guanidinopropionic acid was acquired from Sigma-Aldrich (\#G 6878) and mixed with normal chow from Harlan (\#2018) to make a 1\% $\beta$-GPA mixture $(17-19,73)$. Body weight was measured every $3^{\text {rd }}$ day $(2 x$ week). Food intake was measured at those times to track food consumption. The average mouse and food weight of each cage was calculated at the end of each week to track body weight gain and food consumption, repetitively. 
Muscle Size - The gastrocnemius complex (soleus, plantaris, and the two heads of the gastroc) was surgically dissected tendon-to-tendon and any fat around the tissue was removed before the muscle was weighed. Because of the likelihood that body mass change is accompanied by a change in muscle mass, muscle mass was normalized to body weight, skeletal muscle protein concentration, and tibia length.

ATP Determination - We used Invitrogen Detection Technologies' ATP Determination Kit (A22066). This is a bioluminescence assay for quantitative determination of ATP with recombinant firefly luciferase and its substrate Dluciferin. Amount of ATP was calculated in the experimental samples from a provided standard curve.

Homogenizing of Muscle - At a later time muscles tissue were homogenized in 10x homogenizing buffer. Homogenizing buffer consisted of $10 \mu \mathrm{l} / \mathrm{ml}$ protease inhibitor, $1 \mu \mathrm{l} / \mathrm{ml}$ DTT, $5 \mu \mathrm{l} / \mathrm{ml}$ Benzamidine, $2.5 \mu \mathrm{l} / \mathrm{ml}$ Sodium Vanadate, and the rest was made up of CHAPS buffer. A $50 \mu \mathrm{l}$ aliquot of the total homogenate was placed in a separate tube with $50 \mu \mathrm{l}$ of sample buffer for totally lysate analysis. The remaining homogenates were spun at $1000 \times \mathrm{x}$ for $10 \mathrm{~min} @ 4{ }^{\circ} \mathrm{C}$. The supernatant was taken and placed in separate tubes and the remaining pellet will be discarded. An aliquot of $10 \mu \mathrm{l}$ was taken of the samples for a protein assay while the rest was stored in an $-80^{\circ} \mathrm{C}$ freezer.

Protein Determination - A Bovine serum albumin was used to determine protein concentration of the muscle samples using the Commassie Stain Assay (Thermo Scientific). The plate was run through the plate reader $(595 \mathrm{~nm})$ to calculate protein concentration. A workable dilution was calculated for each sample that was used in subsequent Western Blot analysis.

Immunoprecipitation - The sample was processed in CHAPS buffer and $500 \mu \mathrm{g}$ of $1000 x$ supernatant was combined with elF-4E or mTOR antibody and mixed 
overnight. Immune complexes were isolated with a goat anti-rabbit or -mouse BioMag IgG beads (Qaigen), using a magnetic stand. Precipitates were eluted in SDS sample buffer, boiled, pelleted by magnet, collected, and subjected to standard Western analysis for elF-4E, elF-4G, and 4E-BP1 (elF-4E IPs only) or mTOR and raptor (mTOR IPs only). mTOR's association with raptor was analyzed from mTOR immunoprecipitates, and elF-4E and 4E-BP1 associated with elF-4E was examined in elF-4E immunoprecipitates.

Western Analysis - Degree of activation of AMPK, mTOR and their substrates raptor, S6K1 (total and phospho), 4E-BP1 (total and phospho), rpS6, eEF-2, GSK3- $\alpha / \beta$, p-Akt (Ser 473 and Thr 308), total Akt, and ACC were analyzed by Western analysis from skeletal muscle homogenates. Results were normalized to $\beta$-Tubulin. TOR, raptor, S6K1 (total/phospho), GSK3 $\alpha / \beta$, and ACC were run on a $7 \%$ gel. BP1 (total/phospho), eEF-2, and p-Akt (Ser473/Thr 308), and total Akt were run on a $4-12 \%$ gel. AMPK (phospho), PGC-1 $\alpha$, COXIV, $\beta$-Tubulin, and rpS6 (phospho) were run on a 12\% gel. Equal protein was resolved by SDSPAGE (NuPAGE; Invitrogen). A kaleidoscope marker was used to visually determine protein placement based on weight $(\mathrm{kDa})$. Gels ran for $\sim 90$ minutes at $125 \mathrm{~V}$ in cold room until samples have run the length of the gel. They were transferred to PVDF membrane for 75 minutes at $30 \mathrm{~V}$. The resulting membranes were blocked in $5 \%$ milk ( 5 grams dehydrated milk/100 ml TBST) for $60 \mathrm{~min}$ at room temperature. Membranes were rinsed $4 \times 10$ minutes with $1 \times$ TBST, then incubated with the appropriate primary antibody diluted in 1x TBST over night in cold room. The next day membranes were rinsed $3 \times 5$ min with $1 x$ TBST then rocked in their respective HRP-conjugated-secondary antibodies diluted in 5\% milk in TBST. All primary and secondary antibodies were purchased through Cell Signaling Technology Inc. Immunoblots were visualized via ECL or ECLAdvanced and captured by a camera-integrated system (SynGene). Concentration of protein expression was assessed by ImageJ software. Results will then be compared to percent of the control. 


\section{Statistics}

All data are expressed as mean \pm standard error of the mean. Comparisons are made to the lean controls, using a one- or two-way (body weight and food intake only) ANOVA analysis (Prism v3.0 software; GraphPad Software). The significance level is $\mathrm{P}<0.05$. 


\section{Results}

mTOR Signaling Activation in Ob/ob Mouse Skeletal Muscle. Previous studies $(40,54,90)$ have reported that obese mouse models have elevated mTOR signaling under fasted conditions. In support of our model, we examined mTOR signaling activation of TORC1 substrates S6K1 and rpS6 in various skeletal muscles of the lower limb from both lean and ob/ob mice (Fig 1). We examined predominantly mixed, slow, and fast contractile-type muscles (gastrocnemius, soleus, and tibialis anterior respectively). All three muscles types displayed elevated mTOR signaling under fasted conditions compared to muscles from lean counterparts.

AMPK and ACC Phosphorylation. Following a $12 \mathrm{hr}$ fast, activation of AMP Kinase (AMPK), on the phosphorylation site T172 and its substrate acetyl-CoA carboxylase $(A C C)$ on the $S 79$ phosphorylation site was determined by western blot analysis to verify the efficacy of the obese model and the treatment with the AMPK agonist $\beta$-GPA. Unlike previous investigations, including our own, there was no statistically significant difference between the levels of AMPK T172 and ACC S79 phosphorylation in OC mice to LC mice (Fig 2a). Following 8 weeks of feeding with $\beta$-GPA mixed chow and a $12 \mathrm{hr}$ fast, the fasted obese skeletal muscle AMPK phosphorylation increased significantly above those of the LC mice. ACC phosphorylation levels significantly increased compared to the OC mice (Fig 2a).

ATP. ATP was found to be significantly less in the skeletal muscle of both lean and ob/ob groups fed $1 \% \beta$-GPA, compared to their respective control groups (Fig $2 b$ ). Since $\beta$-GPA is a known creatine kinase competitor, driving down ATP levels, this data is a positive indicator, along with increased AMPK (p), of the efficacy of our treatment.

Body Mass and Food Intake Between Groups. Body mass was measured in each mouse $2 x$ a week. Comparisons were made using a Two Way ANOVA 
analysis. LF and OC mice displayed significant differences in body mass throughout the 8 weeks of feeding with the means for LF and OC mice being $42.1 \%$ lighter and $86.3 \%$ heavier, respectively, than that of LC mice (Table 1). The OF mice decreased in weight to the point of there being no significant difference to the weight of the LC mice during week 4 (Fig 3). This reduction in weight remained until week 6 where the OF mice started to regain weight $(\sim 5 \mathrm{~g})$. However, despite this gain they remained $29.0 \%$ lighter than the OC mice and only $32.3 \%$ heavier than LC mice (Table 1 ) after 8 weeks on the $1 \% \beta$-GPA. Food intake between groups also increased in the LC, LF, and OC groups (Fig 4). The OF group ate the least for the first 4 weeks then their intake increased to where it was similar with LC mice by 8 weeks. This corresponds with the OF mice having no significant difference in body weight to the LC mice during weeks 4-6 then significantly increased weight gain for the last 2 weeks of the study.

Gastrocnemius Complex Muscle Characteristics. The gastrocnemius complex (including the soleus, plantaris, and the medial and lateral heads of the gastrocnemius muscles) skeletal muscle weight was significantly lower in the OC mice compared to the LC group (Table 1). We then compared muscle weight relative to body mass and found that this resulted in a ratio that was $59.0 \%$ lower than that of LC (Table 1). After 8 weeks of $\beta$-GPA feeding, the OF group's gastrocnemius complex muscle weight was $43.3 \%$ lower than that of the LC mice (Table 1) and significantly less than OC (Table 1). However, relative to body mass, this resulted in an increase of $5.3 \%$ over OC mice (Table 1 ).

Tibial length was measured in each group. Though statistical significance was found in both treated groups, it should be noted that there is very little variance between groups (Table 1). One mouse in the OF group was excluded from analysis because the tibia was more than two standard deviations away from the mean. When comparing muscle weight to tibial length the ratio between the LF and OF groups was $39.8 \%$ and $23.5 \%$ lower than LC mice, respectively (Table 1). 
PGC-1 $\alpha$ and COX IV. Western analysis of total muscle lysates for PGC-1 $1 \alpha$ protein expression, a strong indicator of oxidative metabolism, showed no difference between lean and ob/ob control mice (Fig 5a). Following 8 weeks of $1 \% \beta$-GPA feeding there was no change in either lean or ob/ob mice(Fig $5 a)$. COXIV, an indicator of mitochondrial function, was analyzed via western analysis of total muscle lysates. Again, no difference was found between lean and ob/ob control mice or experimental groups (Fig 5b).

Translational Initiation Complex. Proper formation of the translation initiation complex is crucial for accruing of muscle mass. Therefore, after 8 weeks of $1 \%$ $\beta$-GPA fed conditions, translation initiation complex (i.e. elF-4F) formation was examined in elF-4E immunoprecipitates from lean and obese (ob/ob) gastrocnemius complex muscle lysates. elF-4G association with elF-4E showed no difference between lean and ob/ob mice regardless of treatment (Fig 6). Total 4E-BP1 associated with elF-4E showed an increasing trend with $1 \% \beta$-GPA feeding in both lean and ob/ob mice but statistical significance was not reached in either group (Fig 6).

TORC1 Signaling. The mammalian Target of Rapamycin (mTOR) protein is a major regulator of cell size by complexing and activating several components of mRNA translation initiation and elongation. TORC1 complex of mTOR contains the rapamycin-sensitive protein raptor, which binds to mTOR to activate TORC1 substrates. After 8 weeks of $\beta$-GPA fed conditions, raptor was examined in mTOR immunoprecipitates from lean and obese (ob/ob) gastrocnemius complex muscles. Raptor associated with mTOR was lower in OC mice compared to LC (Fig 7).

Analysis of TORC1 downstream targets 4E-BP1, S6K1, and its substrate ribosomal protein S6 (rpS6) was also conducted by western blot in total cell lysates. Following 8 week $\beta$-GPA feeding and under fasted conditions, the 
activation of the elF4E binding protein, 4E-BP1, was significantly higher in the LF and OF groups compared to Lean mice (Fig 8a). Total 4E-BP1 showed the same trend though there was no statistical significance found.

The T389 phosphorylation site of S6K1 was lower in OF mice versus OC mice returning its activation to lean levels (Fig 8b). No significant difference was found in total S6K1 or rpS6 on the S240/244 phosphorylation site. A substrate of S6K1, eukaryotic elongation factor (eEF) 2, regulates elongation during mRNA translation. We analyzed eEF-2 on the T56 phosphorylation site where it was found to not differ between LC and OC groups (Fig 8c).

TORC2 Signaling. PKB, otherwise known as Akt, is a downstream target of the rapamycin insensitive component of mTOR, rictor, at the $\$ 473$ phosphorylation site. After 8 weeks of $\beta$-GPA fed conditions, total Akt and the phosphorylation sites, T308 and S473 were found to be not significantly different between groups in fasted skeletal muscle (Fig 9a). A downstream target of Akt, GSK3, is inhibited by Akt phosphorylation. GSK3- $\beta$ isoform is responsible for inhibiting glycogen synthase (53). GSK3- $\beta$ was analyzed in fasted skeletal muscle after 8 weeks of $\beta$-GPA fed conditions. GSK3- $\beta$ phosphorylation was found to be significantly decreased in the OF group compared to OC (Fig 9b). 


\section{Discussion}

Many of the health problems associated with obesity, such as, lipotoxicity, dyslipidemia, type 2 diabetes, and chronic inflammation, have significant negative impacts on skeletal muscle function. This decrease in function is due to muscle atrophy induced by obesity (54). Loss of muscle mass is a result of an imbalance between the rates of protein synthesis and degradation (3). The mammalian Target of Rapamycin, mTOR responds in the presence of adequate nutrients to increase RNA translation and protein synthesis, initiating the growth process $(4,5,41,68,84)$. However, in obesity, despite excess nutrients and elevated mTOR signaling, atrophy remains $(6,27,38,63,67,72)$. Therefore, the goal of this study was to determine if continuous, long term (8 week) feeding with chow mixed with the AMPK agonist-mTOR antagonist, $\beta$-GPA, would normalize mTOR signaling and mTOR-related processes (i.e. growth) in obese mouse skeletal muscle to that of lean mice. The results of the present study show that long term $\beta$-GPA feeding to ob/ob mice can normalize aspects of hyperactive mTOR-related signaling. This attenuation of mTOR signaling following the 8 week feeding in the obese skeletal muscle can account for some of the improvement seen in gastrocnemius muscle and total body mass. Therefore, these data show that feeding ob/ob mice a 1\% $\beta$-GPA mixed diet (AMPK agonist) for 8 weeks helps normalize regulatory processes controlling muscle mass. Thus creating a more positive anabolic environment for the muscle that is sensitive and capable to growth stimuli.

Our aim in using the well established AMPK agonist, $\beta$-GPA, was to counter the harmful side effects that obesity has on skeletal muscle. Skeletal muscle that displays dyslipidemia, type 2 diabetes, and/or obesity has been shown to be less responsive to growth stimuli $(40,54,90)$. $\beta$-GPA decreases muscle creatine levels $(17,73)$ by acting as a competitor. ATP is then broken down creating higher levels of AMP, subsequently increasing AMPK activation $(17,95)$. Correspondingly, in the current study, 8 weeks of $\beta$-GPA feeding increased AMPK (p) T172 and its substrate, ACC (p) T79, in lean and ob/ob mice 
(Fig 2). Therefore, $\beta$-GPA feeding is an effective means by which to improve obese skeletal metabolism and growth related signaling. Though previously known to be an AMPK agonist $(17-19,73,95)$, to our knowledge this is the first study to use $\beta$-GPA to promote growth in obese skeletal muscle.

Reduced skeletal muscle size has been associated with obesity in animals $(38,39)$ and humans $(57)$, despite an up-regulation of the growth-promoting mTOR pathway $(6,27,38,63,67,72)$, which these data corroborate (Table 1 and Fig 8 \& 9). However, skeletal muscle mass in relation with body mass increased in the $\beta$-GPA fed ob/ob mice by $5.7 \%$ (versus ob/ob control mice), however, this change did not reach significance (Table 1). Given that the half-life of mixed mouse muscle is $\sim 21$ days $(75,87)$ and the dramatic reductions in body mass that were observed in the $\beta$-GPA fed ob/ob mice over the 8 week feeding period (Table 1), a greater increase in muscle mass was anticipated. Ob/ob mice fed $\beta$-GPA did not differ significantly in body weight from lean control mice between 4-6 weeks of feeding (Table 1). After which, their food intake increased and they began to regain weight (Table 1). It is possible that had we examined muscle weight between 4-6 weeks as opposed to 8 weeks, we would have seen a larger muscle mass to body mass ratio.

Previous research in obese skeletal muscle has focused on understanding the metabolic state of the muscle, such as hyperinsulinemia, hyperglycmia, insulin sensitivity, glucose disposal, dyslipidemia, and glycogen metabolism (25, $28,40,58,82,88,94,96)$. In the current study we examined several indicators of metabolic function within the skeletal muscle of obese mice. The current data show that AMPK (p) T72 was elevated in ob/ob mice after 8 weeks of feeding with of $\beta$-GPA, which regulates glucose metabolism and gluconeogenesis (66). The rate limiting enzyme in fatty acid oxidation, ACC (p) T79 (83), was also elevated in the $\beta$-GPA fed ob/ob mice. This suggests that 8 weeks of $\beta$-GPA feeding in ob/ob mice increases the efficiency of energy utilization within these animals. $\beta$-GPA fed ob/ob mice showed a 22.5 and $24 \%$ increase in PGC- $1 \alpha$ and 
COX IV, respectively, compared to control ob/ob mice (Fig 5). PGC-1 $\alpha$ and COX IV are good indicators of oxidative metabolism and mitochondrial function, respectively $(11,93)$. Together, these data suggest that 8 weeks of $\beta$-GPA feeding improves the metabolic function of skeletal muscle in ob/ob mice.

The increased potential for growth in ob/ob mice in the current study comes from the changes in mTOR signaling as a result of $\beta$-GPA feeding. Though no changes in raptor associated with mTOR were seen (Fig 7), there were alterations in the downstream machinery of mTORC1 signaling. S6K1 (p) T389 was reduced to levels equivalent to those of the lean control mice (Fig 8b). S6K1 is used as an indicator of mTORC1 activity and is shown to be elevated in ob/ob mice (54). Rivas et al. - 2009 showed that following a high fat diet, S6K1 was elevated by $20 \%$ at T389 and this increase was totally reversed following exercise training (i.e. AMPK activation) (67). Elevated S6K1 results in an increase in IRS-1 phosphorylation through negative feedback, decreasing insulin sensitivity and ultimately giving rise to insulin resistance in chronic situations (67). In mice that are S6K1 deficient, there is a protective effect against obesity and insulin resistance because of an upregulation in oxidative phosphorylation and insulin sensitivity (90). Therefore, its lower activation seen after 8 weeks of $\beta$-GPA in ob/ob mice in the current study is suggestive of more normalized mTOR signaling and some protective effect against insulin resistance.

Interestingly, another mTORC1 substrate, 4E-BP1, was significantly increased in ob/ob mice fed $\beta$-GPA. 4E-BP1 regulates $40 S$ ribosome binding to mRNA by increasing the availability of elF-4E (78). When 4E-BP1 is phosphorylated it releases elF-4E allowing it to bind with elF-4G and subsequently to the $40 \mathrm{~S}$ ribosomal subunit (78). A rise in 4E-BP1 was seen in our previous data after 2 weeks of injections with the AMPK kinase activator AICAR. It is unclear at this time what role an increase in 4E-BP1 after treatment with an AMPK kinase activator means. One thought is that 4E-BP1 acts to protect against excessive fat deposition and insulin resistance. Le Bacquer et al 
showed that in 4E-BP1 and 4E-BP2 double knock out (DKO) mice gained significantly more body mass as well as fat mass than their wild type counterparts (46). When a high fat diet was fed to these DKO mice, insulin resistance was promoted to a greater extent than in the wild type mice (46). It could be that the increase in 4E-BP1 that we observed is a protective measure to guard against the ob/ob mice regaining the fat mass that they had lost in regards to the $\beta$-GPA feeding. In DKO mice, S6K1 phosphorylation was significantly increased, suggesting that, though both are downstream of mTORC1, and may have a role in influencing each other (46). Our current data are supportive of this thought given the reciprocal changes in 4E-BP1 and S6K1 with $\beta$-GPA treatment.

We also examined 4E-BP1 within the elF-4F complex in hopes of determining what role it plays in obese skeletal muscle. No significant changes occurred in elF-4G or 4E-BP1 within the 4F complex following 8 weeks of feeding with $\beta$-GPA in ob/ob mice (Fig 6). Though 4E-BP1 is phosphorylated by mTORC1, it is not the only signaling pathway that influences 4E-BP1. Protein kinase $\mathrm{C} \delta(\mathrm{PKC} \delta$ ) and the Erk pathway have also been shown to phosphorylate $4 \mathrm{E}-\mathrm{BP} 1(30,45)$. Insulin has also been shown to regulate the phosphorylation of 4E-BP1 through the phosphitidylinositol 3-kinase (PI 3-kinase) signaling pathway, which is dependent on the phosphorylation and activation of protein kinase $B$ (PKB)/Akt (22, 80, 91). Had we analyzed skeletal muscle under fed conditions, we may have observed lower 4E-BP1 in our elF-4E IPs, providing an alternative perspective to our treatment. However, determining the exact role 4E-BP1 plays in obese skeletal muscle remains unclear at this time.

The other binding component of mTOR, rictor, is rapamycin insensitive. TORC2 controls the phosphorylation of PKB/Akt (70) that acts as a negative feedback regulator of TORC1 activation (6). In the current data, there were no significant changes in Akt found in ob/ob mice after 8 the week $\beta$-GPA feeding. Rictor knock out (RImKO) mice function normally but display slight decreases in the amount of raptor (4). In these RImKO mice Akt is still phosphorylated on Ser 
473 so TORC2 is not solely responsible for Akt phosphorylation. Also, Akt is hypothesized to play a role in the degree of raptor expression (4). No change in Akt in the current study could account for the lack of change seen in raptor's association with mTOR. However, the downstream target of Akt, GSK3 $\beta$, which inhibits glycogen synthase $(33,52)$, was significantly reduced in ob/ob mice after $\beta$-GPA feeding. Since Akt was unchanged following $\beta$-GPA feeding in ob/ob mice in the current study, there could be another controller of GSK3 activity. S6K1 has been shown to regulate GSK3 upon the loss of TSC1-2 (99) in vitro, but more work needs to be done to determine any association in vivo between the two.

In conclusion, 8 weeks of $\beta$-GPA feeding caused decreases in body mass in ob/ob mice, which was accompanied by a slight increase in skeletal muscle mass. The obese mouse muscle was more metabolically active following $\beta$-GPA feeding, evidenced by elevated AMPK (p) T72 and ACC (p) S79 levels. $\beta$-GPA feeding did return certain downstream targets of mTORC 1 and 2 signaling (S6K1 (p) T389 and GSK3) to a level that is comparative with that of their lean counterparts, which exerts a potential protective effect against regaining fat mass. Taken together, it is feasible that $\beta$-GPA feeding returns ob/ob skeletal muscle to a state in which growth can be attained under the proper stimulus (i.e. exercise or nutrition), not unlike their lean counterparts. 


\section{Table 1}

\begin{tabular}{|c|c|c|c|c|}
\hline |유 & | & $\left.\right|_{\pi}$ & 片 & \\
\hline $\begin{array}{l}\vec{\Delta} \\
\dot{\vec{\omega}} \\
0 \\
1+ \\
\stackrel{N}{\omega} \\
\vec{\omega} \\
\stackrel{*}{+}\end{array}$ & $\begin{array}{l}0 \\
\infty \\
\text { ஸै } \\
1+ \\
0 \\
0 \\
\text { ట్ }\end{array}$ & $\begin{array}{l}\vec{\rho} \\
\vec{\omega} \\
1+ \\
\overrightarrow{\vec{v}} \\
\overrightarrow{\text { जे }}\end{array}$ & $\begin{array}{l}\stackrel{\omega}{\vec{N}} \\
\underset{0}{0} \\
1+ \\
\stackrel{0}{O}\end{array}$ & 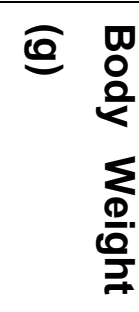 \\
\hline $\begin{array}{l}0 \\
0 \\
0 \\
1+ \\
0 \\
0 \\
0 \\
+ \\
+\end{array}$ & $\begin{array}{l}\vec{N} \\
\stackrel{\vec{U}}{\vec{H}} \\
\vec{H} \\
\dot{\omega} \\
\dot{\omega}\end{array}$ & $\begin{array}{l}0 \\
N \\
\stackrel{1}{1} \\
1+ \\
\omega \\
\phi \\
*\end{array}$ & $\begin{array}{l}\overrightarrow{0} \\
\infty \\
\text { G } \\
+ \\
\text { or } \\
\sigma\end{array}$ & 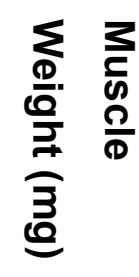 \\
\hline $\begin{array}{l}\vec{v} \\
0 \\
1+ \\
0 \\
\stackrel{+}{+} \\
+ \\
+\end{array}$ & $\begin{array}{l}\overrightarrow{0} \\
\text { or } \\
+ \\
0 \\
0\end{array}$ & $\begin{array}{l}\vec{\infty} \\
\overrightarrow{\vec{H}} \\
\dot{+} \\
\stackrel{\sim}{N} \\
*\end{array}$ & $\begin{array}{l}\vec{\infty} \\
\underset{1}{V} \\
+ \\
0 \\
\stackrel{D}{0}\end{array}$ & 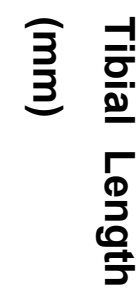 \\
\hline $\begin{array}{l}\infty \\
\infty \\
1+ \\
0 \\
\text { or } \\
*\end{array}$ & $\begin{array}{l}N \\
\omega \\
+ \\
+ \\
H \\
N \\
0\end{array}$ & $\begin{array}{l}\vec{N} \\
0 \\
1+ \\
\text { O } \\
\text { or } \\
*\end{array}$ & $\begin{array}{l}\underset{ \pm}{ \pm} \\
\underset{1+}{+} \\
\vec{D}\end{array}$ & 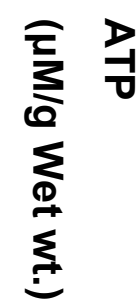 \\
\hline $\begin{array}{l}N \\
\text { N } \\
1+ \\
O \\
\text { i } \\
*\end{array}$ & $\begin{array}{l}\stackrel{N}{\vec{H}} \\
\stackrel{+}{O} \\
\stackrel{*}{*}\end{array}$ & $\begin{array}{l}\text { or } \\
\text { N } \\
1+ \\
\text { Oे } \\
\text { N }\end{array}$ & $\begin{array}{l}\text { or } \\
\vec{H} \\
\dot{H} \\
\stackrel{\sim}{N}\end{array}$ & 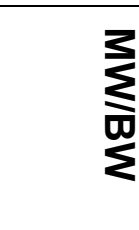 \\
\hline $\begin{array}{l}0 \\
\dot{0} \\
1+ \\
\circ \\
\dot{\omega} \\
+ \\
+\end{array}$ & $\begin{array}{l}\text { o) } \\
\text { o } \\
1+ \\
\text { Oे } \\
\text { or }\end{array}$ & $\begin{array}{l}\text { or } \\
\overrightarrow{I+} \\
\stackrel{0}{\text { N }} \\
*\end{array}$ & $\begin{array}{l}\infty \\
0 \\
1+ \\
0 \\
\omega\end{array}$ & $\underset{=1}{\underline{\Sigma}}$ \\
\hline
\end{tabular}


Figure 1

\section{Gastrocnemius}

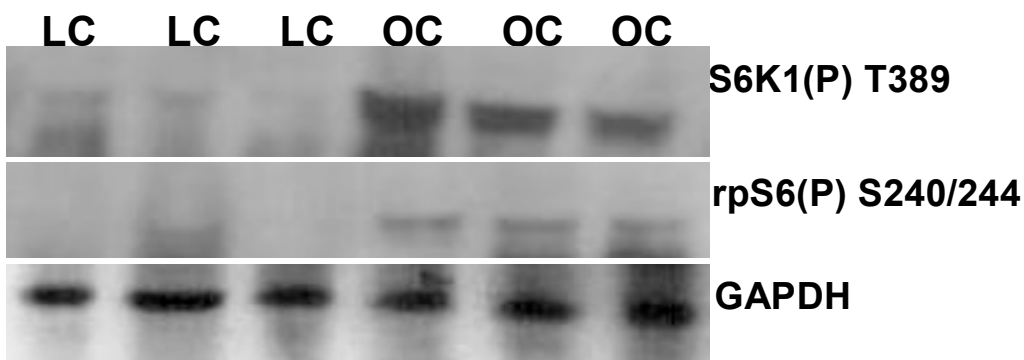

\section{Soleus}

LC LC OC OC

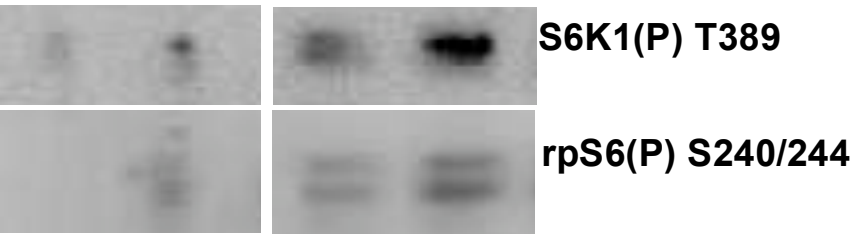

Tibialis Anterior

LC LC OC OC

S6K1(P) T389 
Figure 2

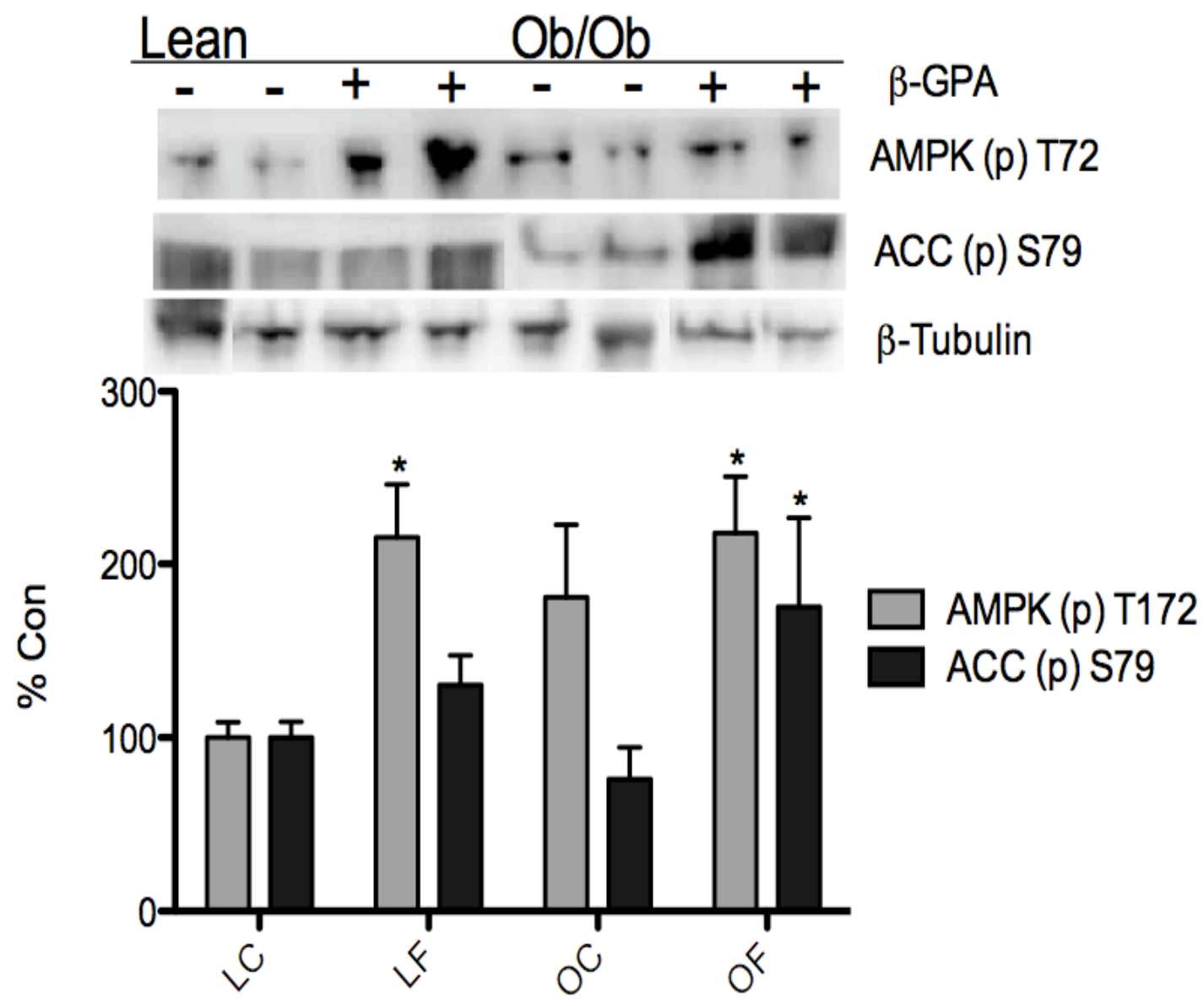


Figure 3

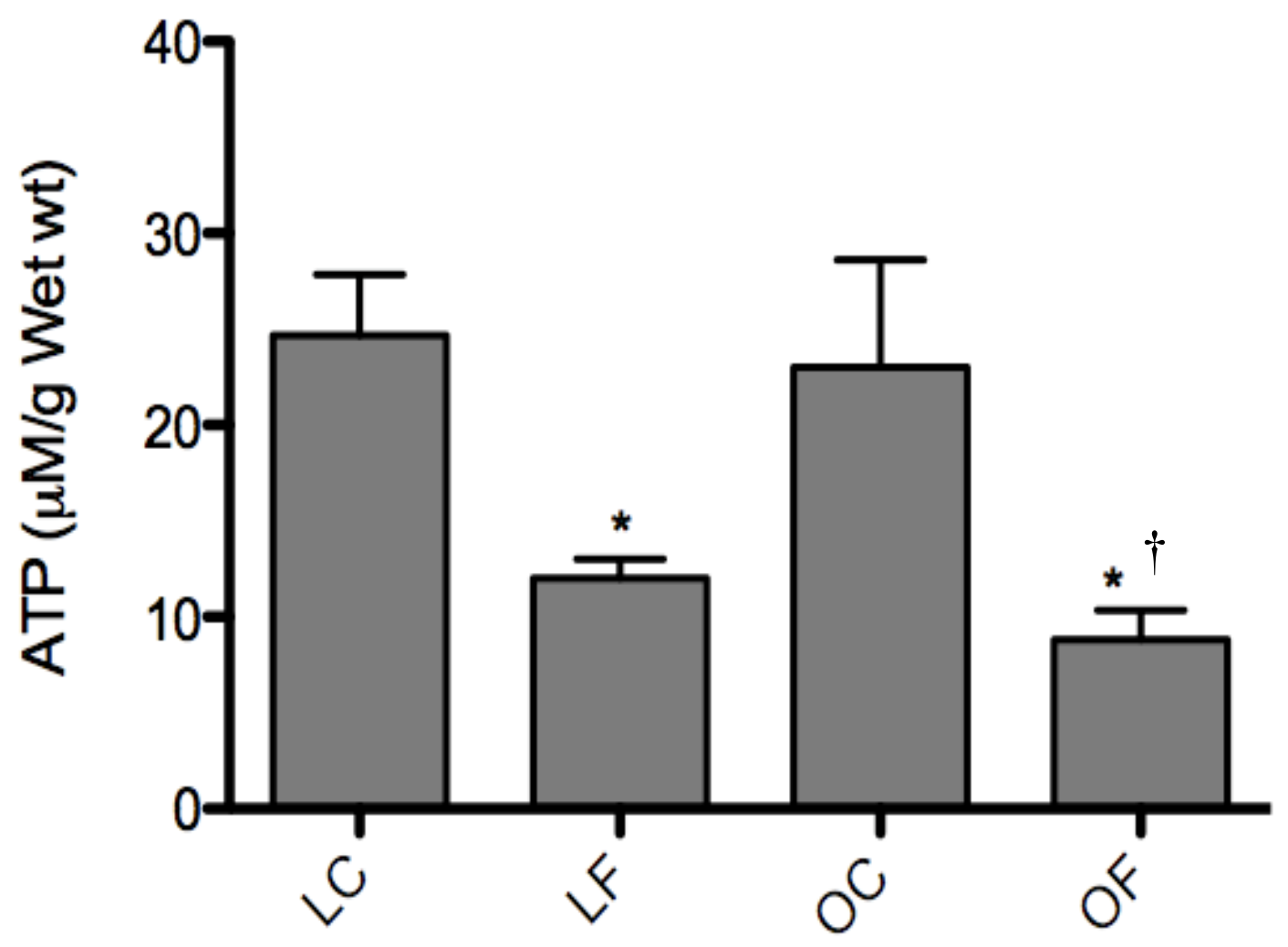


Figure 4

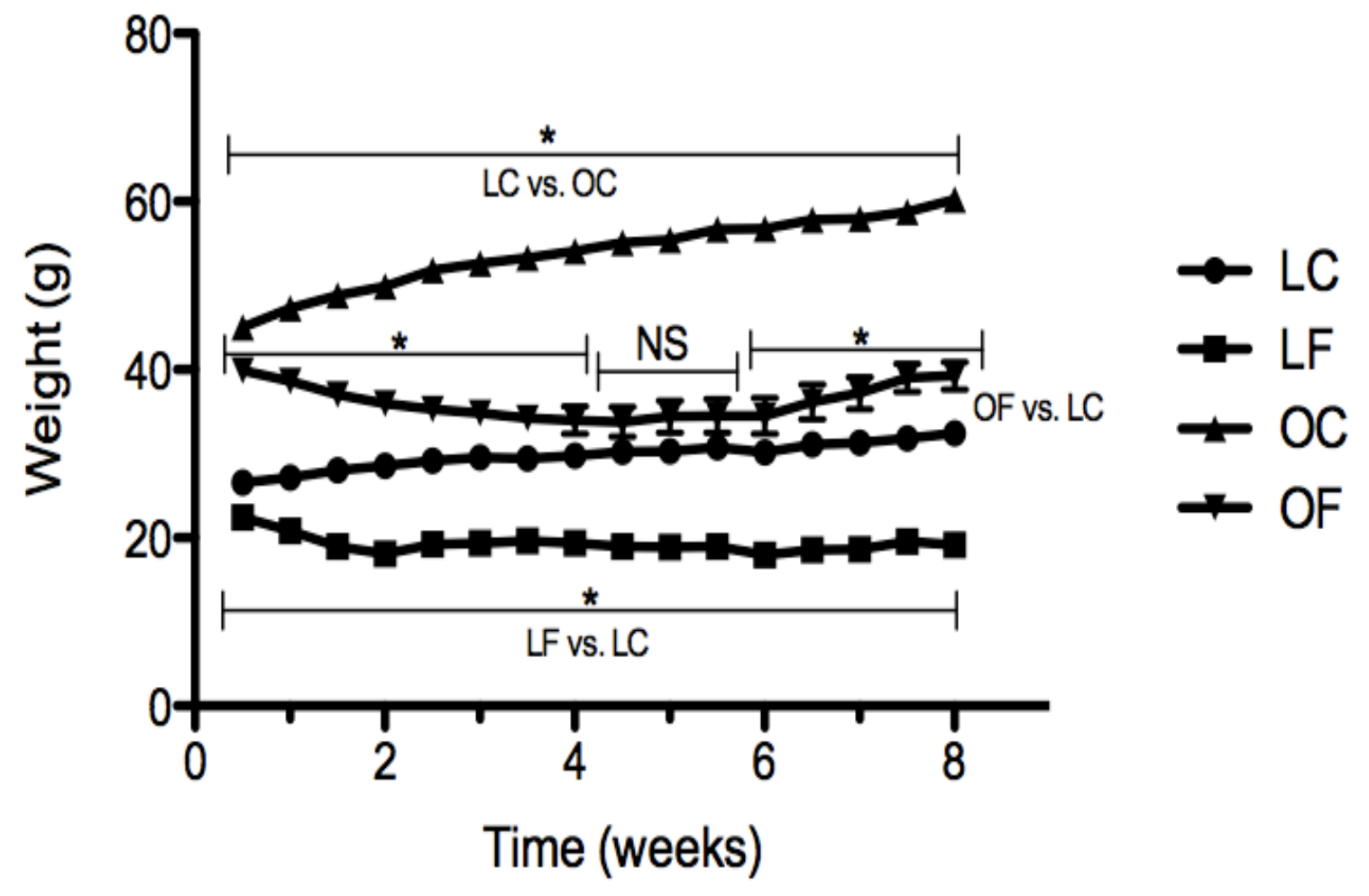


Figure 5

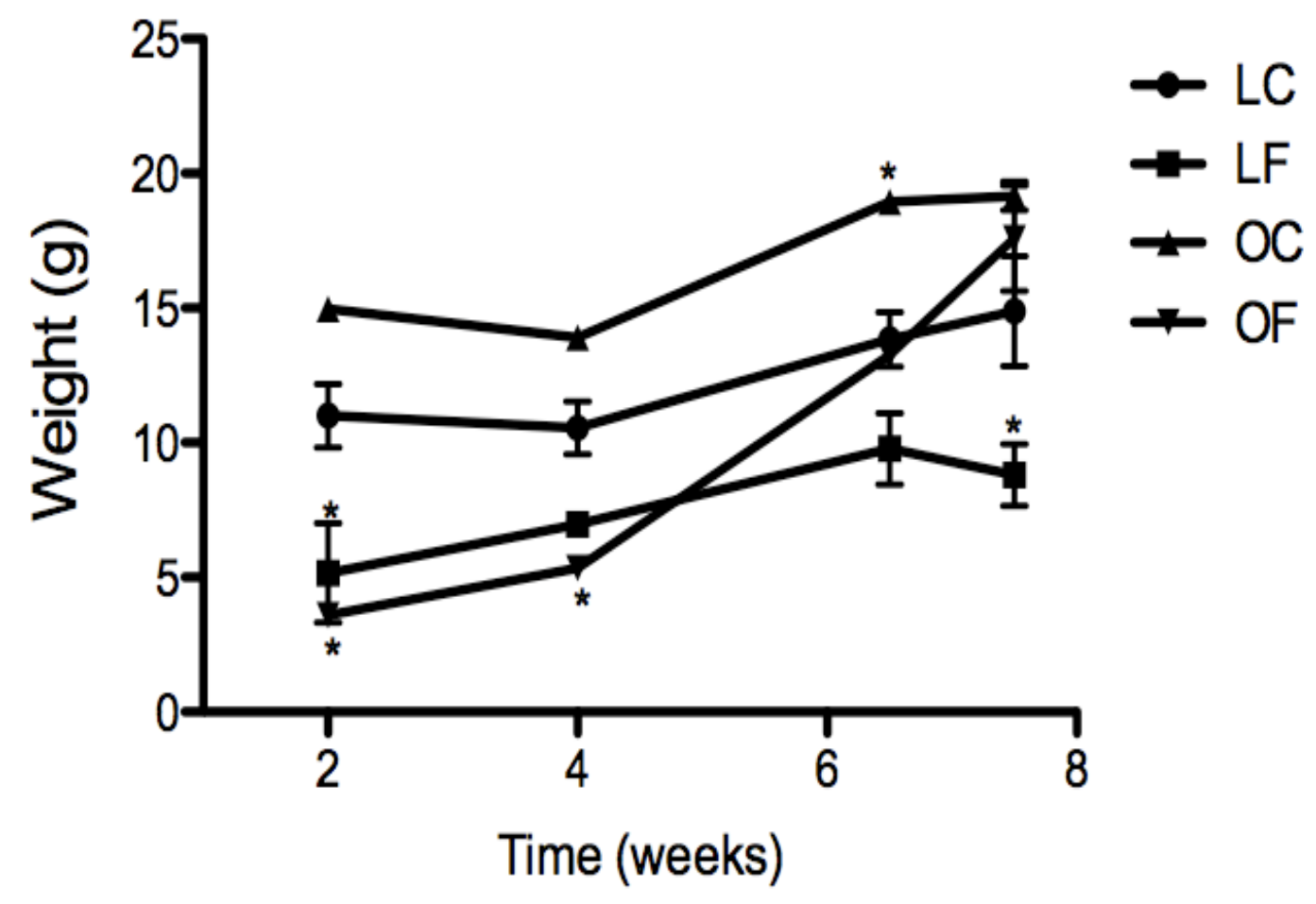


Figure 6
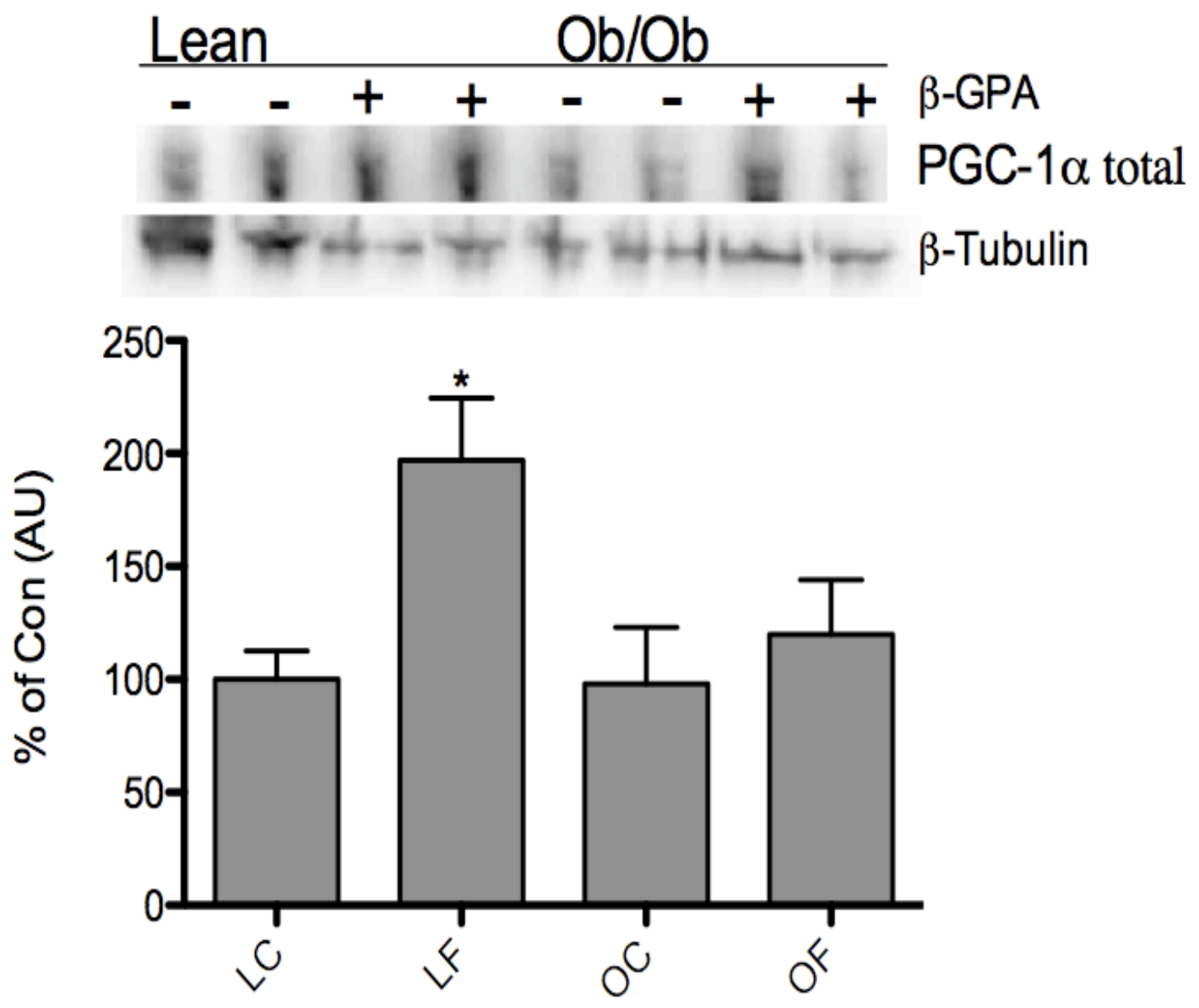
Figure 7

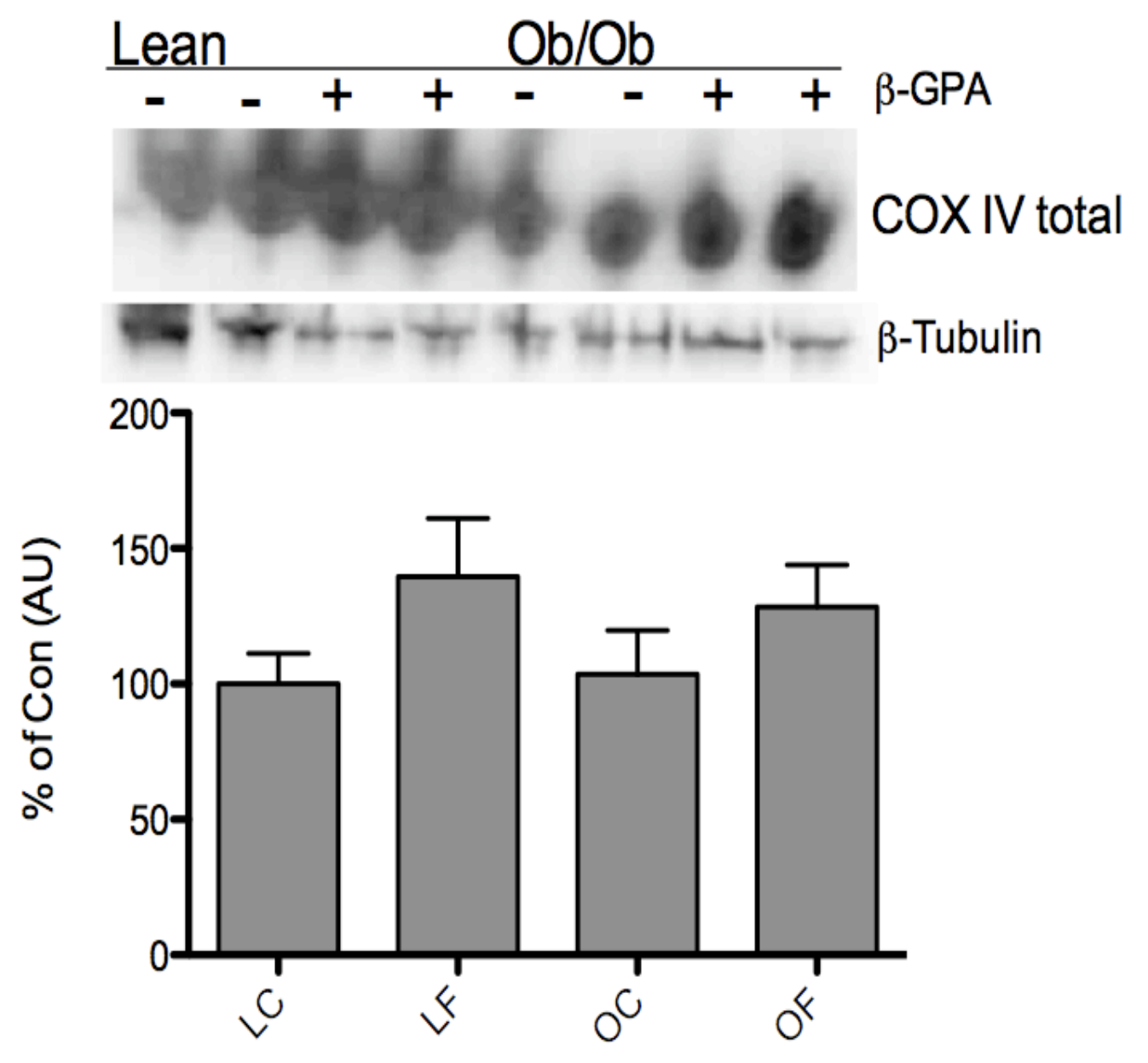


Figure 8

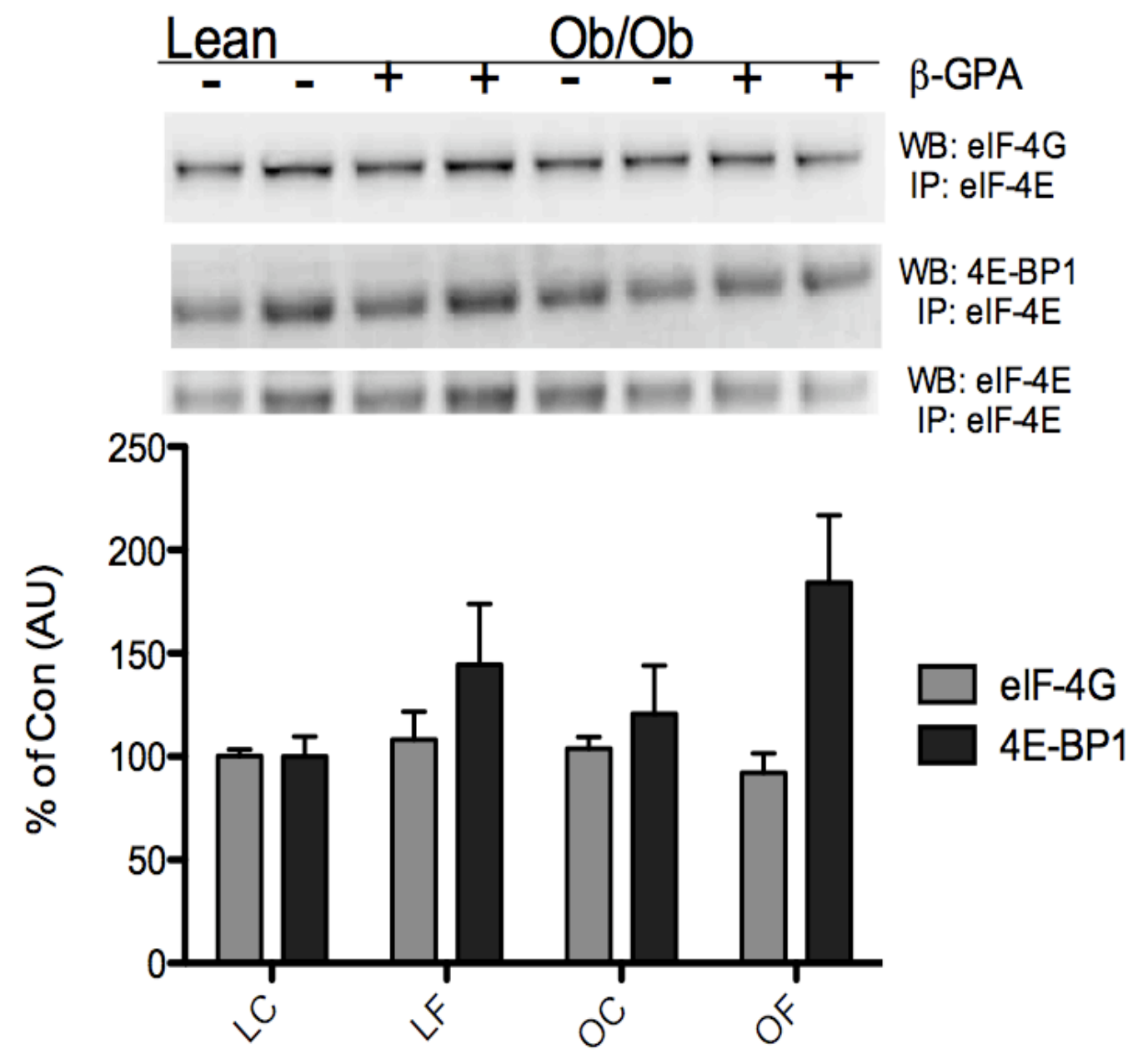


Figure 9
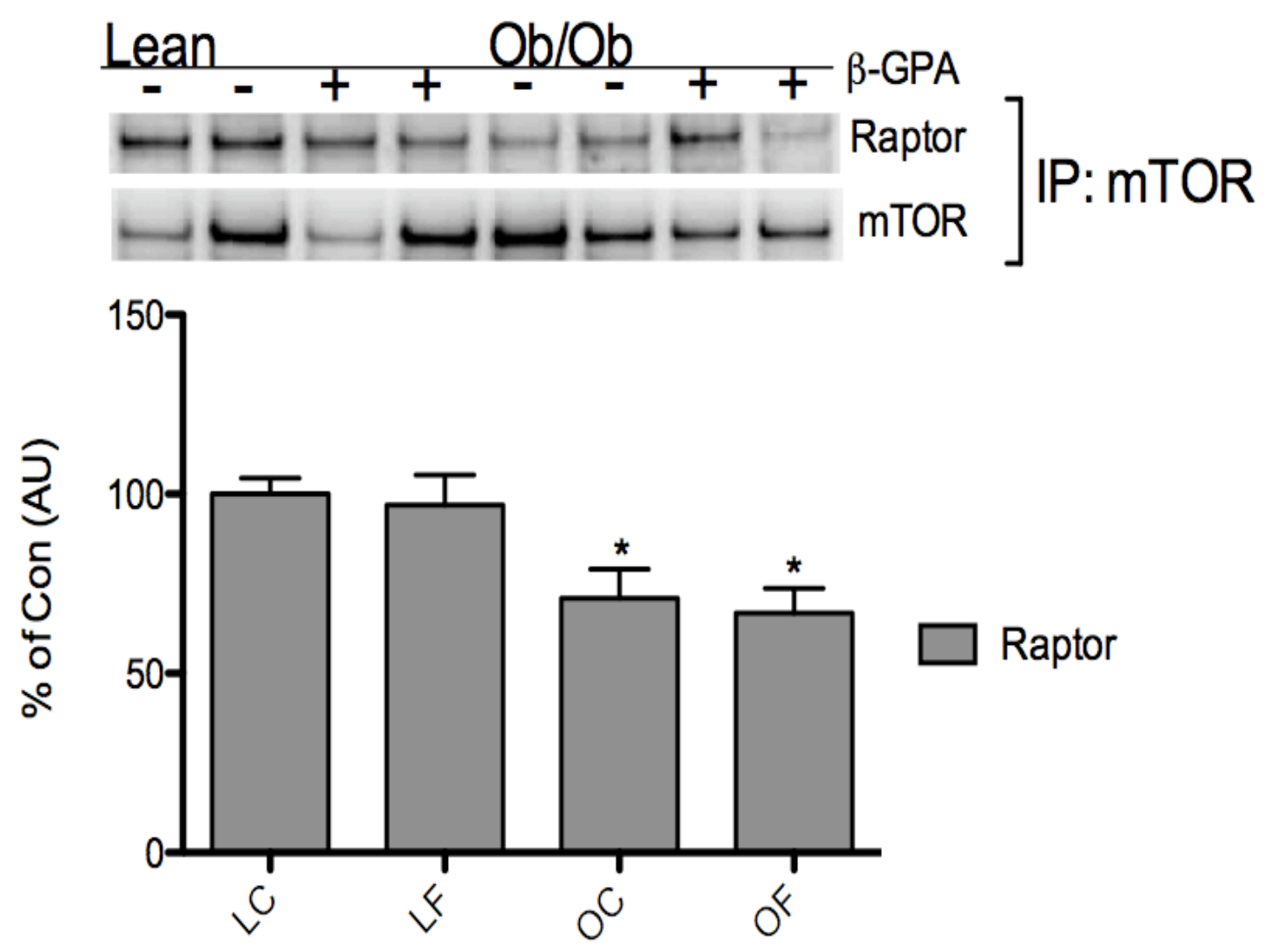
Figure 10

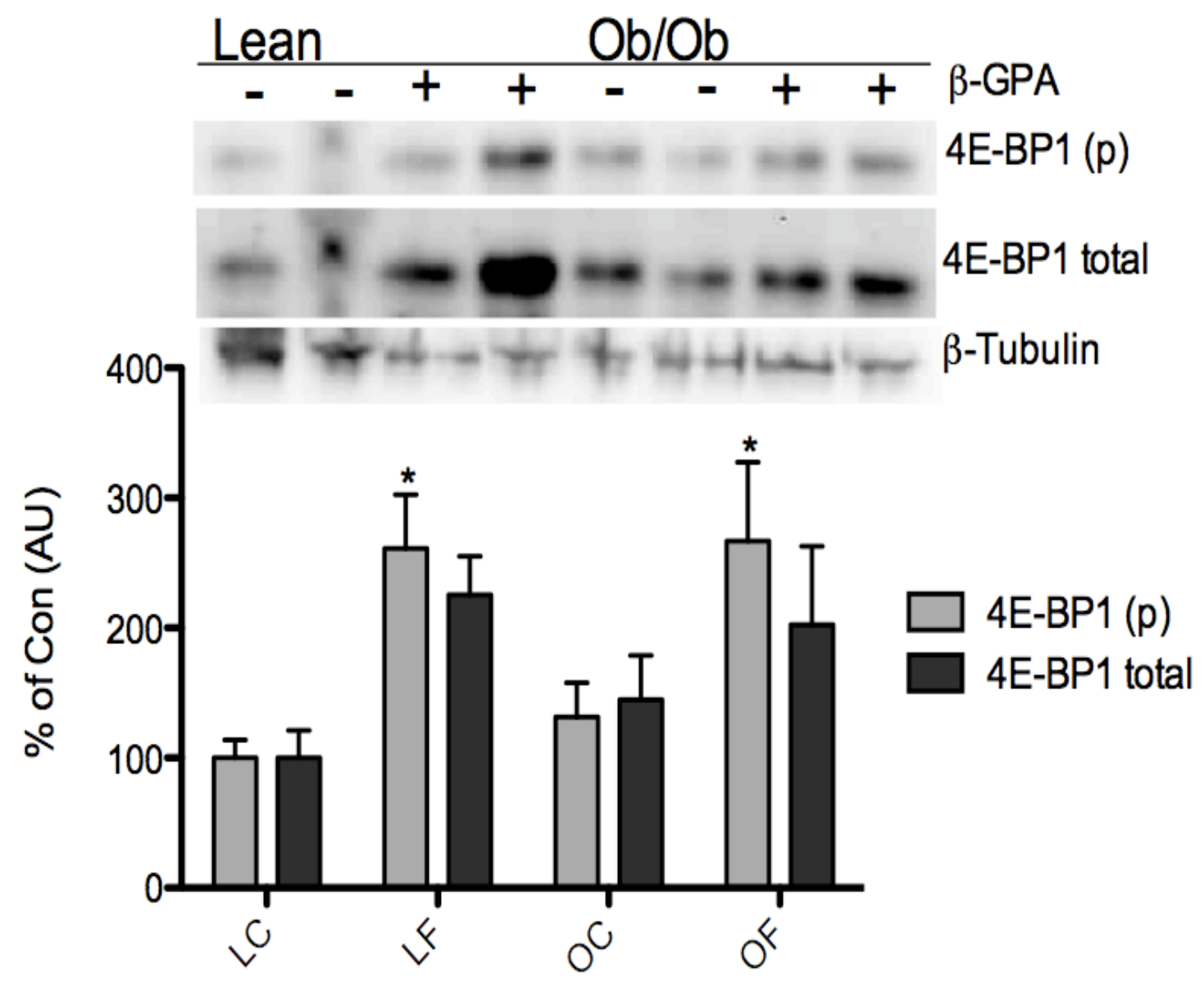


Figure 11
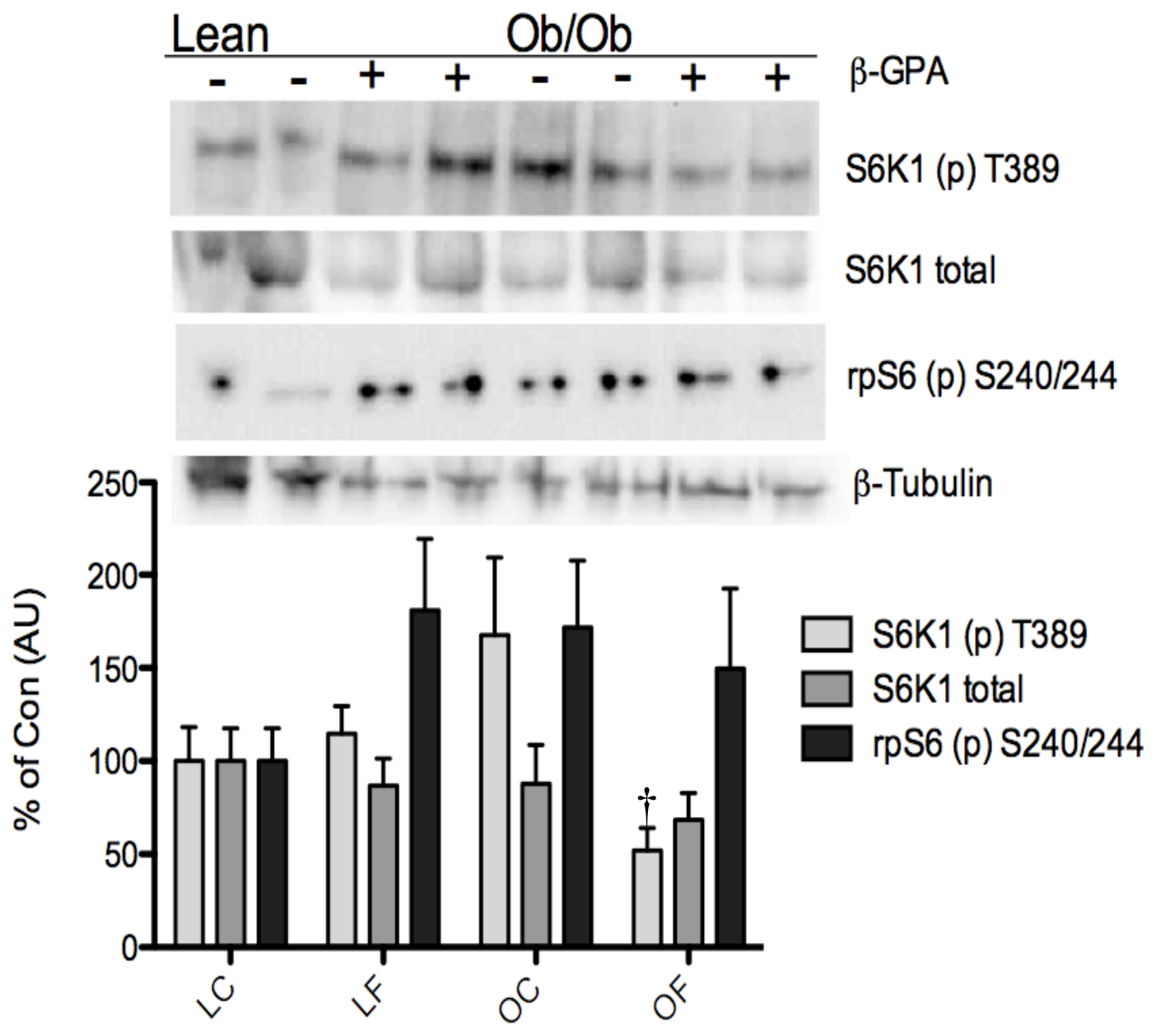
Figure 12

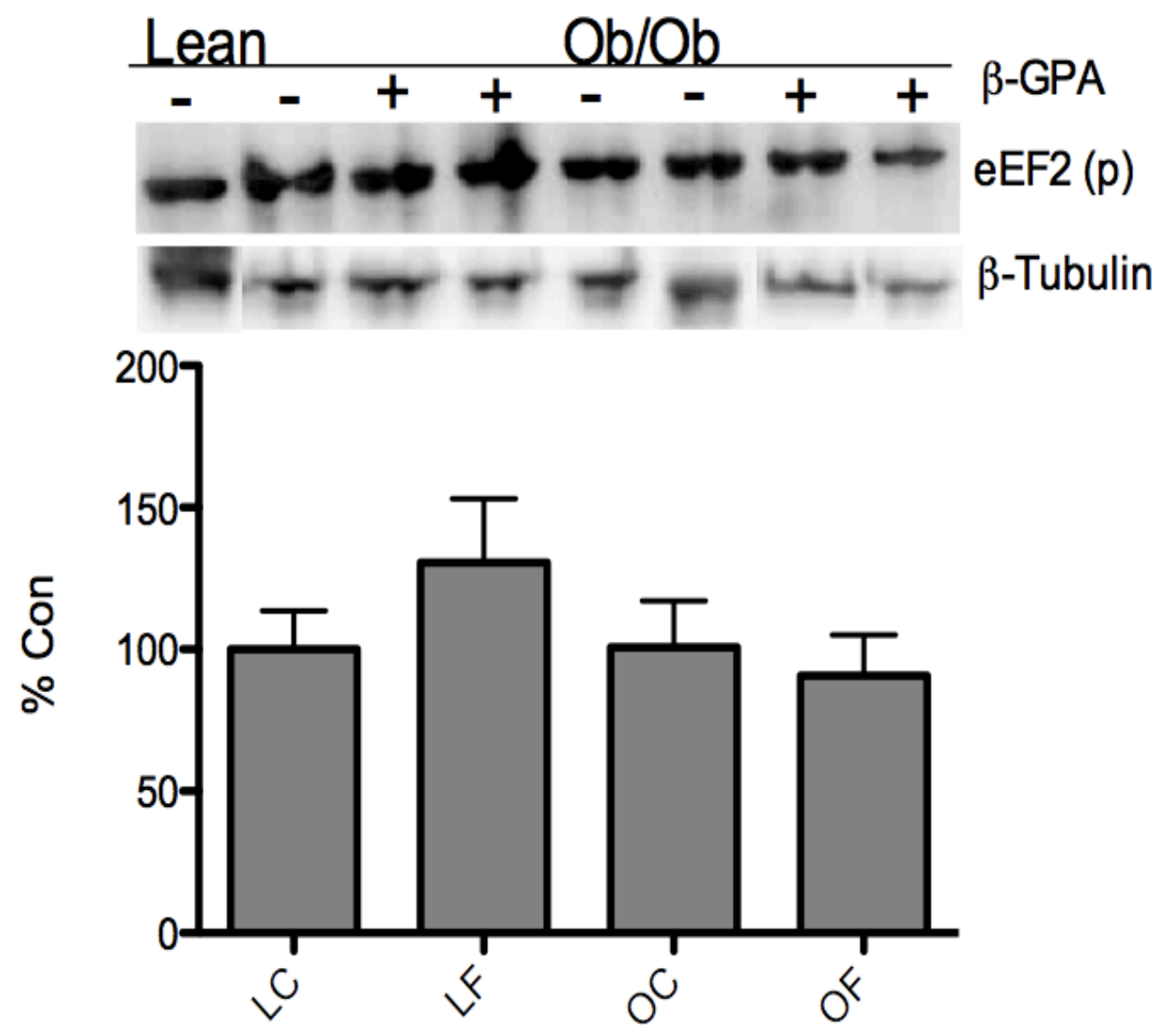


Figure 13

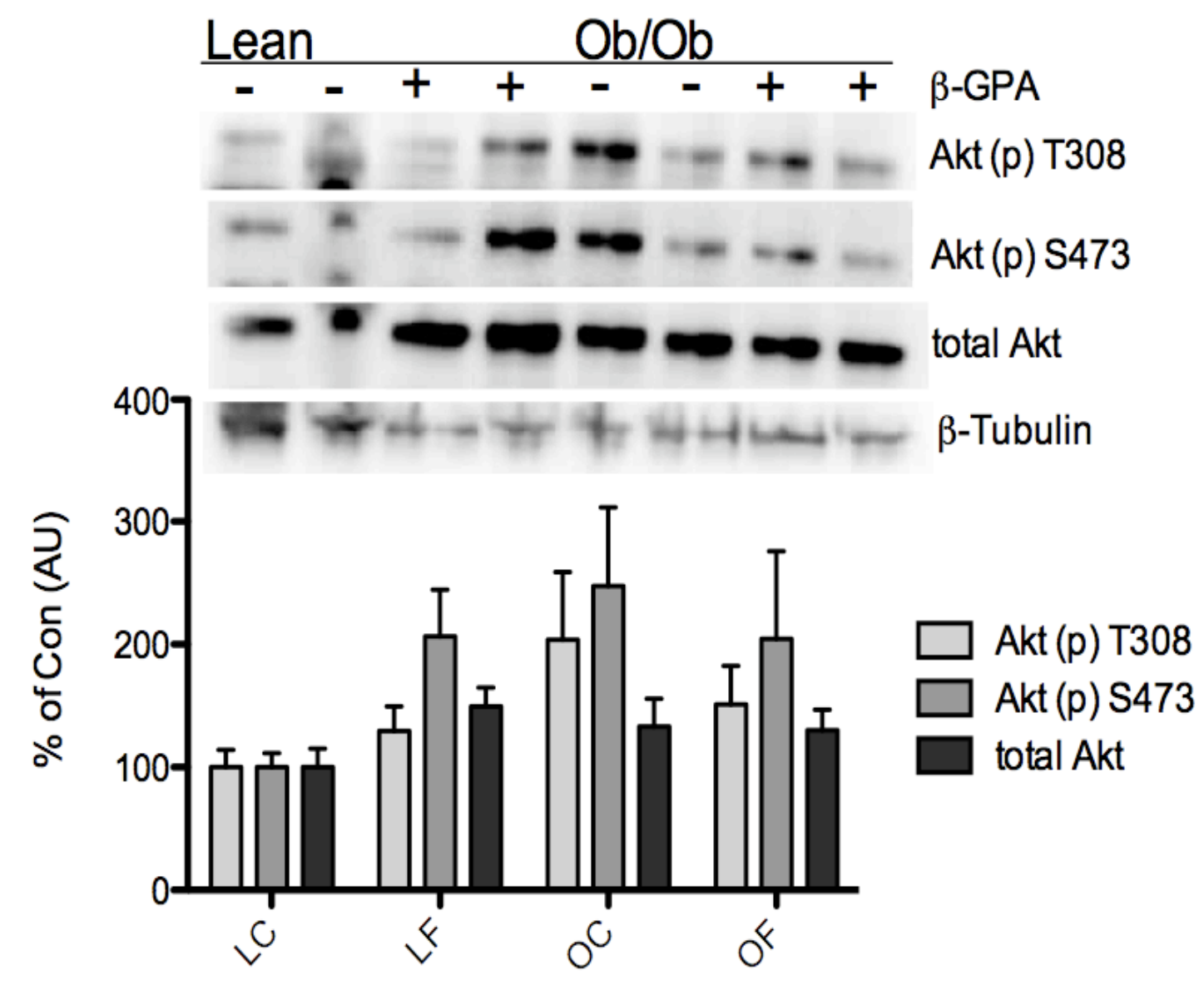


Figure 14

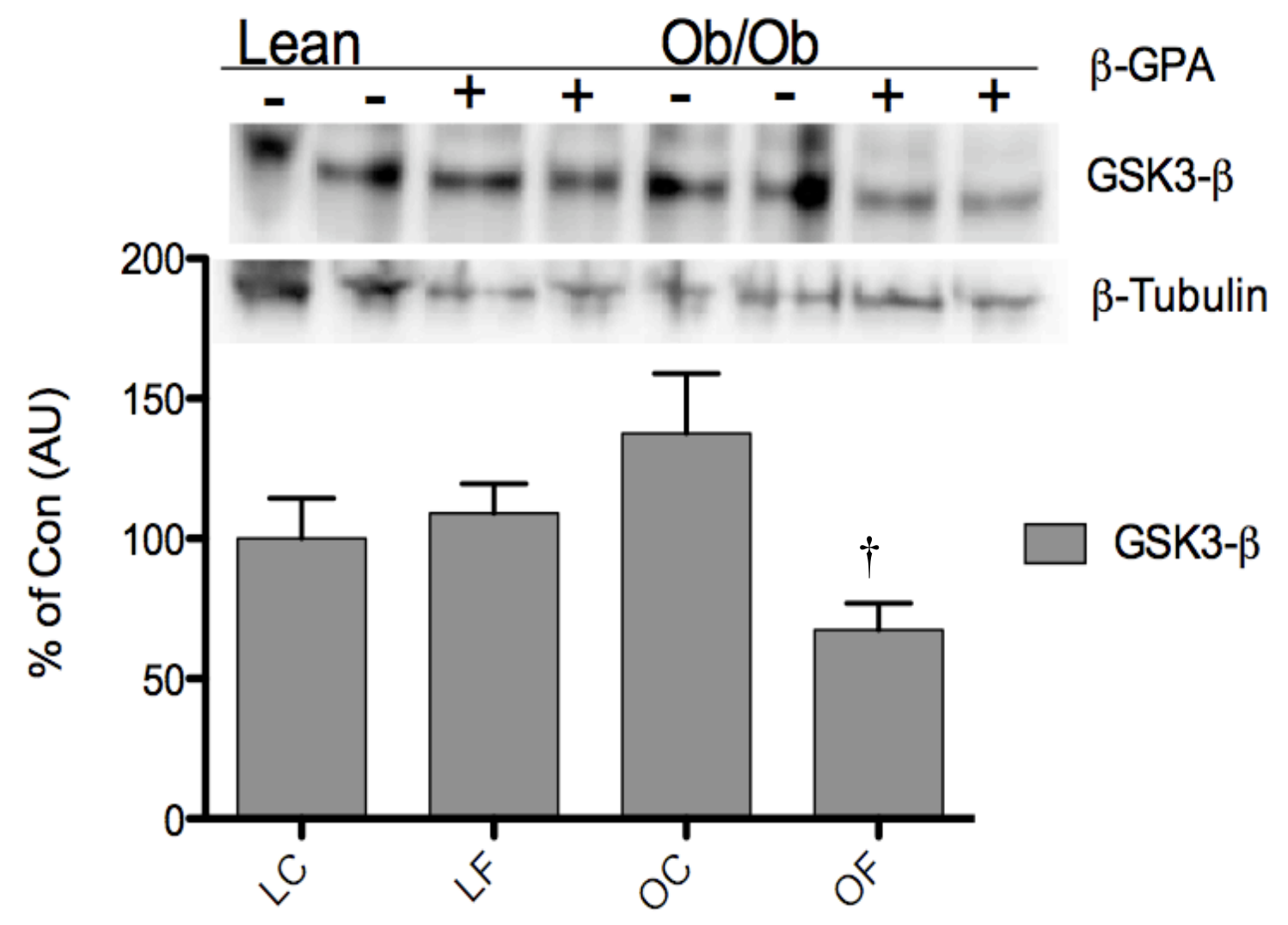


Figure 15

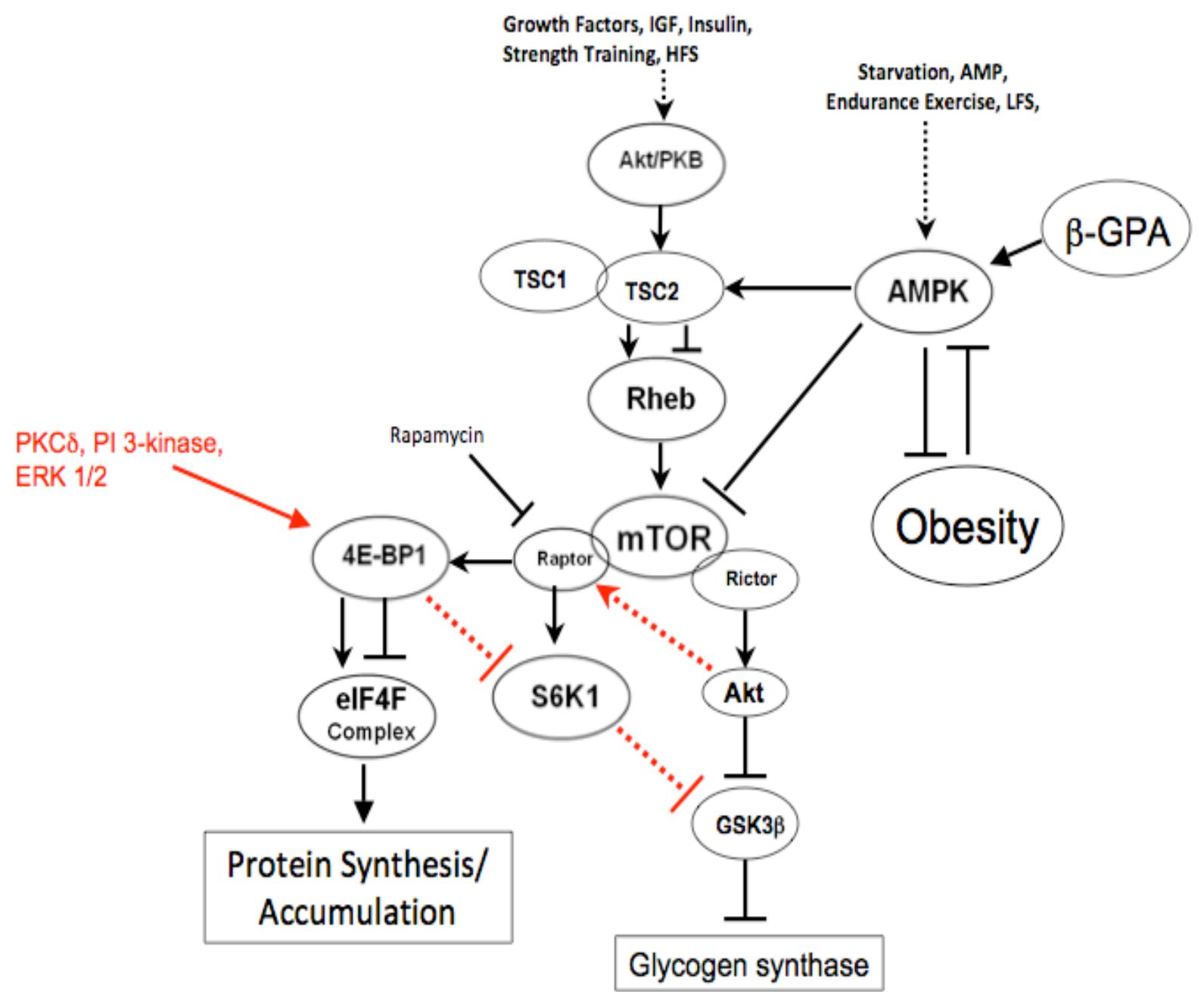




\section{Figure Legends}

Figure 1. Fasted mTOR signaling in lean and ob/ob skeletal muscles. Equal protein from lean and ob/ob male mice gastrocnemius, soleus, and tibialis anterior muscle homogenates were analyzed by Western blot methods for S6K1 T389 and rpS6 S240/244 phosphorylation sites and normalized to GAPDH. $\mathrm{LC}=$ lean control, $\mathrm{OC}=\mathrm{ob} / \mathrm{ob}$ control. Representative Western blots are shown.

Figure 2. Long term ( 8 wk) $\beta$-GPA feeding increases fasted AMPK signaling in ob/ob gastrocnemius muscle. Following 8 weeks of feeding with $1 \% \beta$-GPA mixed chow, equal protein from lean and ob/ob male mice gastrocnemius muscle homogenates were analyzed by Western blot methods for AMPK T172 and ACC S79 phosphorylation sites and normalized to $\beta$-Tubulin (expressed as a percent of LC). LC=lean control, LF $=\beta$-GPA fed diet, $O C=0 b / o b$ control, OF= $\beta$-GPA fed diet. Representative Western blots are shown. $P<0.05$ ( $n=8$ per group, except OC $n=7$ in $p$-AMPK, 1 mouse was removed because it was more than 2 standard deviations from the mean).

Figure 3. Long term (8 wk) $\beta$-GPA feeding decreases ATP levels in ob/ob gastrocnemius muscle. Bioluminescence assay for quantitative determination of ATP with recombinant firefly luciferase and its substrate D-luciferin. Amount of ATP was calculated in the experimental samples from a provided standard curve. Comparisons made using Two-way ANOVA with Bonferroni statistical analysis to LC. $L C=l e a n$ control, $L F=\beta-G P A$ fed diet, $O C=0 b / o b$ control, OF= $\beta-G P A$ fed diet. $P<0.05$ ( $n=8$ per group)

Figure 4. Long term (8 wk) $\beta$-GPA feeding attenuates weight gain in lean and ob/ob mice. During 8 weeks of feeding with $1 \% \beta$-GPA mixed chow body weight was measured twice weekly as well as post feeding before sacrificing. Data shows mean weight per treatment plus standard error of the mean. Comparisons made using Two-way ANOVA with Bonferroni statistical analysis to 
LC. $L C=$ lean control, $L F=\beta-G P A$ fed diet, $O C=o b / o b$ control, $O F=\beta-G P A$ fed diet. $P<0.05$ versus $L C$ ( $n=8$ per group)

Figure 5. Food intake during ( 8 wk) $\beta$-GPA feeding between lean and ob/ob groups. Mean weight of food from each cage eaten at weeks 2, 4, 6.5, and 7.5 are shown with standard error of the mean. Comparisons made using Two-way ANOVA with Bonferroni statistical analysis to LC. LC=lean control, LF $=\beta-G P A$ fed diet, $\mathrm{OC}=\mathrm{ob} / \mathrm{ob}$ control, $\mathrm{OF}=\beta-\mathrm{GPA}$ fed diet. $\mathrm{P}<0.05$ versus $\mathrm{LC}(\mathrm{n}=8$ per group).

Figure 6. Long term ( 8 wk) $\beta$-GPA feeding does not change PGC-1 $\alpha$ activation in ob/ob mice. Following 8 weeks of feeding with $1 \% \beta$-GPA mixed chow, equal protein from lean and ob/ob male mice gastrocnemius muscle homogenates were analyzed by Western blot methods for PGC-1 $\alpha$ and normalized to $\beta$-Tubulin. The results are expressed as a percentage of LC. Percent difference of LF to LC and OF to OC is shown. Representative Western blots are shown. Comparisons made using One-way ANOVA with Tukey's statistical analysis. $\mathrm{LC}=$ lean control, $\mathrm{LF}=\beta-\mathrm{GPA}$ fed diet, $\mathrm{OC}=\mathrm{ob} / \mathrm{ob}$ control, $O F=\beta$-GPA fed diet. $P<0.05$ versus $L C$ ( $n=8$ per group).

Figure 7. Long term ( 8 wk) $\beta$-GPA feeding does not change COXIV activation in ob/ob mice. Following 8 weeks of feeding with $1 \% \beta$-GPA mixed chow, equal protein from lean and ob/ob male mice gastrocnemius muscle homogenates were analyzed by Western blot methods for COX IV and normalized to $\beta$-Tubulin. The results are expressed as a percentage of LC. Percent difference of LF to LC and OF to OC is shown. Representative Western blots are shown. Comparisons made using One-way ANOVA with Tukey's statistical analysis. $\mathrm{LC}=$ lean control, $\mathrm{LF}=\beta-\mathrm{GPA}$ fed diet, $\mathrm{OC}=\mathrm{ob} / \mathrm{ob}$ control, $O F=\beta$-GPA fed diet. $P<0.05$ versus $L C$ ( $n=8$ per group). 
Figure 8. Long term ( 8 wk) $\beta$-GPA feeding does not alter elF-4F complex formation in ob/ob mice. Following 8 weeks of feeding with $1 \% \beta$-GPA mixed chow, equal protein from lean and ob/ob male mice gastrocnemius muscle homogenates was immunoprecipitated with an elF-4E antibody, as described in Methods, and the immunoprecipitates (IP) were assessed for elF-4G, 4E-BP1, and elF-4E content by immunoblot (WB) analysis, and the ratio of elF-4G to elF$4 \mathrm{E}$ and $4 \mathrm{E}-\mathrm{BP} 1$ to elF4E was calculated. The results are expressed as a percentage of LC. Representative Western blots are shown. Comparisons made using One-way ANOVA with Tukey's statistical analysis. LC=lean control, LF $=\beta$ GPA fed diet, OC=ob/ob control, OF $=\beta$-GPA fed diet. $P<0.05$ versus $L C(n=8$ per group).

Figure 9. Long term ( $8 \mathrm{wk}$ ) $\beta$-GPA feeding does not change raptor's association with $\mathbf{m T O R}$ in ob/ob mice. Following 8 weeks of feeding with $1 \%$ $\beta$-GPA mixed chow, equal protein from lean and ob/ob male mice gastrocnemius muscle homogenates was immunoprecipitated with an mTOR antibody, as described in Methods, and the immunoprecipitates (IP) were assessed for raptor and mTOR content by immunoblot (WB) analysis, and the ratio of raptor to mTOR was calculated. The results are expressed as a percentage of LC. Representative Western blots are shown. Comparisons made using One-way ANOVA with Tukey's statistical analysis. $L C=$ lean control, LF $=\beta-G P A$ fed diet, $\mathrm{OC}=\mathrm{ob} / \mathrm{ob}$ control, OF= $\beta$-GPA fed diet. $\mathrm{P}<0.05$ versus $\mathrm{LC}$ ( $\mathrm{n}=8$ per group).

Figure 10. Long term ( $8 \mathrm{wk}) \beta$-GPA increases phosphorylated 4E-BP1 in ob/ob mice. Following 8 weeks of feeding with 1\% $\beta$-GPA mixed chow, equal protein from lean and ob/ob male mice gastrocnemius muscle homogenates were analyzed by Western blot methods for 4E-BP1 ( $p$ ), 4E-BP1 total, and normalized to $\beta$-Tubulin. The results are expressed as a percentage of LC. Representative Western blots are shown. Comparisons made using One-way 
ANOVA with Tukey's statistical analysis. $L C=$ lean control, $L F=\beta-G P A$ fed diet, $\mathrm{OC}=\mathrm{ob} / \mathrm{ob}$ control, OF= $\beta$-GPA fed diet. $\mathrm{P}<0.05$ versus $\mathrm{LC}$ ( $\mathrm{n}=8$ per group).

Figure 11. Long term ( $8 \mathrm{wk}$ ) $\beta$-GPA decreases phosphorylated S6K1 in ob/ob mice. Following 8 weeks of feeding with 1\% $\beta$-GPA mixed chow, equal protein from lean and ob/ob male mice gastrocnemius muscle homogenates were analyzed by Western blot methods for S6K1 T389, S6K1 total, rpS6 S240/244, and normalized to $\beta$-Tubulin. The results are expressed as a percentage of LC. Representative Western blots are shown. Comparisons made using One-way ANOVA with Tukey's statistical analysis. $L C=l e a n$ control, $L F=\beta$ GPA fed diet, OC=ob/ob control, OF $=\beta$-GPA fed diet. $P<0.05$ versus $L C(n=8$ per group, except OC group in S6K1 T389 and rpS6 S240/244 n=7 because one mouse was more than two standard deviations away from the mean).

Figure 12. Long term ( 8 wk) $\beta$-GPA does not change eEF-2 in ob/ob mice. Following 8 weeks of feeding with 1\% $\beta$-GPA mixed chow, equal protein from lean and ob/ob male mice gastrocnemius muscle homogenates were analyzed by Western blot methods for eEF- 2 and normalized to $\beta$-Tubulin. The results are expressed as a percentage of LC. Representative Western blots are shown. Comparisons made using One-way ANOVA with Tukey's statistical analysis. $L C=$ lean control, $L F=\beta-G P A$ fed diet, $O C=o b / o b$ control, $O F=\beta-G P A$ fed diet. $P<$ 0.05 versus $L C$ ( $n=8$ per group).

Figure 13. Long term ( 8 wk) $1 \% \quad \beta$-GPA feeding does not change Akt signaling in ob/ob mice. Following 8 weeks of feeding with $1 \% \beta$-GPA mixed chow, equal protein from lean and ob/ob male mice gastrocnemius muscle homogenates were analyzed by Western blot methods for Akt T308, Akt S473, Akt total, and normalized to $\beta$-Tubulin. The results are expressed as a percentage of LC. Representative Western blots are shown. Comparisons made using One-way ANOVA with Tukey's statistical analysis. LC=lean control, LF= $\beta$ - 
GPA fed diet, OC=ob/ob control, OF $=\beta$-GPA fed diet. $P<0.05$ versus $L C(n=8$ per group, except OC group in Akt T308 and S473 n=7 because one mouse was more than two standard deviations away from the mean).

Figure 14. Long term ( 8 wk) $1 \% \beta$-GPA decreases GSK3 $\beta$ in ob/ob mice. Following 8 weeks of feeding with 1\% $\beta$-GPA mixed chow, equal protein from lean and ob/ob male mice gastrocnemius muscle homogenates were analyzed by Western blot methods for GSK3 $\beta$ and normalized to $\beta$-Tubulin. The results are expressed as a percentage of LC. Representative Western blots are shown. Comparisons made using One-way ANOVA with Tukey's statistical analysis. $\mathrm{LC}=$ lean control, $\mathrm{LF}=\beta$-GPA fed diet, $\mathrm{OC}=\mathrm{ob} / \mathrm{ob}$ control, OF= $\beta$-GPA fed diet. $\mathrm{P}<$ 0.05 versus $L C$ ( $n=8$ per group, except OC group $n=7$ because one mouse was more than two standard deviations away from the mean).

Figure 15. Proposed model of growth signaling in obese skeletal muscle following long term ( $8 \mathrm{wk}$ ) $1 \% \beta$-GPA feeding. 


\section{Chapter 5: Discussion of Findings}

\section{Specific Aim 1:}

Our aim in using the well established AMPK agonist, $\beta$-GPA, was to counter the harmful side effects that obesity has on skeletal muscle. Skeletal muscle that displays dyslipidemia, type 2 diabetes, and/or obesity has been shown to be less responsive to growth stimuli $(40,54,90)$. $\beta$-GPA decreases muscle creatine levels $(17,73)$ by acting as a competitor. ATP is then broken down creating higher levels of AMP, subsequently increasing AMPK activation $(17,95)$. Correspondingly, in the current study, 8 weeks of $\beta$-GPA feeding decreased ATP levels and increased AMPK (p) T172 and its substrate, ACC (p) $\mathrm{T79}$, in lean and ob/ob mice (Fig 2a \& b). Though previously known to be an AMPK agonist $(17-19,73,95)$, to our knowledge this is the first study to use $\beta$ GPA to promote growth in obese skeletal muscle.

Reduced skeletal muscle size has been associated with obesity in animals $(38,39)$ and humans $(57)$, despite an up-regulation of the growth-promoting mTOR pathway $(6,27,38,63,67,72)$, which these data corroborate (Table 1 and Fig 8 \& 9). However, skeletal muscle mass in relation with body mass increased in the $\beta$-GPA fed ob/ob mice by $5.7 \%$ (versus ob/ob control mice), however, this change did not reach significance (Table 1). Given that the half-life of mixed mouse muscle is $\sim 21$ days $(75,87)$ and the dramatic reductions in body mass observed in the $\beta$-GPA fed ob/ob mice over the 8 week feeding period (Table 1), a greater increase in muscle mass was anticipated. Muscle mass was also compared to tibial length for each animal (Table 1). Muscle mass to tibial length was similar to the body weight comparisons in that no statistical significance was found. Ob/ob mice fed $\beta$-GPA did not differ significantly in body weight from lean control mice between 4-6 weeks of feeding (Fig 3). After which, their food intake increased and they began to regain weight (Fig $3 \&$ Fig 4 ). It is possible that had we examined muscle weight between 4-6 weeks as opposed to 8 weeks we would have seen a larger muscle mass to body mass ratio since the OF group gained weight after 6 weeks of feeding. 
Food intake was particularly difficult to control for the duration of the study. We only measured what food was left in the tray, not food on the floor of the cage, so there is sure to be a great deal of variability in our recordings. To correct this issue in the future, food needs to be readily available to the animal in a matter that we can insure the exact amount being eaten, for example; placing food within a dish inside the cage itself.

In summary, 8 weeks of $\beta$-GPA feeding in ob/ob mice increases activation of AMPK (p) T72 and its substrate ACC (p) T79 (Fig 2a). The efficacy of the treatment is supported by the significant decrease in the levels of ATP within $\beta$ GPA fed groups (Fig 2b). 8 weeks of $\beta$-GPA feeding in ob/ob mice also causes dramatic decreases in body mass which is accompanied by slight increases in skeletal muscle mass (Table 1). Therefore, $\beta$-GPA feeding is an effective means by which to improve body composition in ob/ob mice.

\section{Specific Aim 2:}

Previous research in obese skeletal muscle has focused mostly on understanding the metabolic state of the muscle, such as hyperinsulinemia, hyperglycemia, insulin sensitivity, glucose disposal, dyslipidemia, and glycogen metabolism $(25,28,40,58,82,88,94,96)$. In the current study we examined several indicators of metabolic function within the skeletal muscle of obese mice. The current data show that AMPK ( $p$ ) T72 was elevated in ob/ob mice after 8 weeks of feeding with of $\beta$-GPA, which regulates glucose metabolism and gluconeogenesis (66). The rate limiting enzyme in fatty acid oxidation, ACC (p) T79 (83), was also elevated in the $\beta$-GPA fed ob/ob mice. This suggests that 8 weeks of $\beta$-GPA feeding in ob/ob mice increases the efficiency of energy utilization within these animals. PGC-1 $\alpha$ and COXIV are good indicators of oxidative metabolism and mitochondrial function, respectively (11, 93). PGC-1 $\alpha$ increased significantly in the lean mice fed $\beta$-GPA but no changes were seen in the ob/ob mice (Fig 5a). No statistical significant changes were seen in COXIV in both groups (Fig $5 b$ ), however, there was a trend toward significance in both 
groups. Together, these data suggest that 8 weeks of $\beta$-GPA feeding improves the metabolic function of skeletal muscle in ob/ob mice.

The increased potential for growth in ob/ob mice in the current study comes from the changes in mTOR signaling as a result of $\beta$-GPA feeding. Though no changes in raptor associated with mTOR were seen (Fig 7), there were alterations in the downstream machinery of mTORC1 signaling. S6K1 (p) T389 was reduced to levels equivalent to those of the lean control mice (Fig 8b). S6K1 is used as an indicator of mTORC1 activity and is shown to be elevated in ob/ob mice (54). Rivas et al. - 2009 showed that following a high fat diet, S6K1 was elevated by $20 \%$ at T389 and this increase was totally reversed following exercise training (i.e. AMPK activation) (67). Elevated S6K1 results in an increase in IRS-1 phosphorylation through negative feedback; decreasing insulin sensitivity and ultimately giving rise to insulin resistance in chronic situations (67). In mice that are S6K1 deficient, there is a protective effect against obesity and insulin resistance because of an upregulation in oxidative phosphorylation and insulin sensitivity (90). Therefore, its lower activation seen after 8 weeks of $\beta$-GPA in ob/ob mice in the current study is suggestive of more normalized mTOR signaling and some protective effect against insulin resistance.

Interestingly, another mTORC1 substrate, 4E-BP1 (p), was significantly increased in ob/ob mice fed $\beta$-GPA (Fig 9a). No statistical significance was seen in total $4 \mathrm{E}-\mathrm{BP} 1$. $4 \mathrm{E}-\mathrm{BP} 1$ regulates $40 \mathrm{~S}$ ribosome binding to $\mathrm{mRNA}$ by increasing the availability of elF-4E (78). When 4E-BP1 is phosphorylated it releases elF$4 \mathrm{E}$ allowing it to bind with elF-4G and subsequently to the $40 \mathrm{~S}$ ribosomal subunit (78). A rise in 4E-BP1 was seen in our previous data after 2 weeks of injections with the AMPK kinase activator AICAR. It is unclear at this time what role an increase in 4E-BP1 after treatment with an AMPK kinase activator means. One thought is that 4E-BP1 acts to protect against excessive fat deposition and insulin resistance. Le Bacquer et al showed that in 4E-BP1 and 4E-BP2 double knock out (DKO) mice gained significantly more body mass as well as fat mass 
than their wild type counterparts (46). When a high fat diet was fed to these DKO mice, insulin resistance was promoted to a greater extent than in the wild type mice (46). It could be that the increase in 4E-BP1 that we observed is a protective measure to guard against the ob/ob mice regaining the fat mass that they had lost in regards to the $\beta$-GPA feeding. In DKO mice, S6K1 phosphorylation was significantly increased, suggesting that, though both are downstream of mTORC1, and may have a role in influencing each other (46). Our current data are supportive of this thought given the reciprocal changes in 4E-BP1 and S6K1 with $\beta$-GPA treatment.

We also examined 4E-BP1 within the elF-4F complex in hopes of determining what role it plays in obese skeletal muscle. No significant changes occurred in elF-4G or 4E-BP1 within the 4F complex following 8 weeks of feeding with $\beta$-GPA in ob/ob mice (Fig 6). Though 4E-BP1 is phosphorylated by mTORC1, it is not the only signaling pathway that influences 4E-BP1. Protein kinase $C \delta(\mathrm{PKC} \delta)$ and the MAP kinase pathway have also been shown to phosphorylated 4E-BP1 $(30,45)$. Insulin has also been shown to regulate the phosphorylation of 4E-BP1 through the phosphitidylinositol 3-kinase (PI 3-kinase) signaling pathway, which is dependent on the phosphorylation and activation of protein kinase B (PKB)/Akt (22, 80, 91). Had we analyzed skeletal muscle under fed conditions, we may have observed lower 4E-BP1 in our elF-4E IPs, providing an alternative perspective to our treatment. However, determining the exact role $4 \mathrm{E}-\mathrm{BP} 1$ plays in obese skeletal muscle remains unclear at this time.

The other binding component of mTOR, rictor, is rapamycin insensitive. TORC2 controls the phosphorylation of PKB/Akt (70) that acts as a negative feedback regulator of TORC1 activation (6). In the current data, there were no significant changes in Akt found in ob/ob mice after 8 the week $\beta$-GPA feeding. Rictor knock out (RImKO) mice function normally but display slight decreases in the amount of raptor (4). In these RImKO mice Akt is still phosphorylated on Ser 473 so TORC2 is not solely responsible for Akt phosphorylation. Also, Akt is 
hypothesized to play a role in the degree of raptor expression (4). No change in Akt in the current study could account for the lack of change seen in raptor's association with mTOR. However, the downstream target of Akt, GSK3 $\beta$, which inhibits glycogen synthase $(33,52)$, was significantly reduced in ob/ob mice after $\beta$-GPA feeding. Since Akt was unchanged following $\beta$-GPA feeding in ob/ob mice in the current study, there could be another controller of GSK3 activity. S6K1 has been shown to regulate GSK3 upon the loss of TSC1-2 (99) in vitro, but more works needs to be done to determine any association in vivo.

In future studies, we would propose to shorten the $\beta$-GPA feeding period to 4-6 weeks, because weight loss in the ob/ob was the greatest at this time. To add to those data we would analyze other pathways that are known to influence 4E-BP1 (Erk, PI-3 kinase, and/or PKC $\delta$ ) in order to determine what is controlling the increase observed in 4E-BP1 following $\beta$-GPA feeding. Moreover, examining the muscles under fed conditions could provide insight into how a known insulin resistant animal (ob/ob mouse) functions following $\beta$-GPA treatment, which would give a more complete picture of translation initiation within obese skeletal muscle. Given the normalization in skeletal muscle metabolism and growth signaling seen in ob/ob mice after $\beta$-GPA feeding in the current data, we would propose to subject these animals to an exercise regime or return them to a normal diet following 4-6 weeks of $\beta$-GPA feeding and examine how they respond to growth stimuli.

In summary, 8 weeks of $\beta$-GPA feeding caused decreases in body mass in ob/ob mice, which was accompanied by a slight increase in skeletal muscle mass. The obese mouse muscle was more metabolically active following $\beta$-GPA feeding, evidenced by elevated AMPK (p) T72 and ACC (p) S79 levels. $\beta$-GPA feeding did return certain downstream targets of mTORC 1 and 2 signaling (S6K1 (p) T389 and GSK3) to a level that is comparative with that of their lean counterparts, which exerts a potential protective effect against regaining fat mass. Taken together, it is feasible that $\beta$-GPA feeding returns ob/ob skeletal 
muscle to a state in which growth can be attained under the proper stimulus (i.e. exercise or nutrition), not unlike their lean counterparts. 
Chapter 6: References

1. Watanabe CK. Studies in the metabolic changes induced by administration of guanidine ases. J Bio Chem. 1917; 33: 253-265.

2. www.CDC.gov. Center for Disease Control and Prevention.

3. Augert G, Monier S, and Le Marchand-Brustel Y. Effect of exercise on protein turnover in muscles of lean and obese mice. Diabetologia 29: 248-253, 1986.

4. Bentzinger CF, Romanino K, Cloetta D, Lin S, Mascarenhas JB, Oliveri F, Xia J, Casanova E, Costa CF, Brink M, Zorzato F, Hall MN, and Ruegg MA. Skeletal muscle-specific ablation of raptor, but not of rictor, causes metabolic changes and results in muscle dystrophy. Cell Metab 8: 411-424, 2008.

5. Bodine SC. mTOR signaling and the molecular adaptation to resistance exercise. Med Sci Sports Exerc 38: 1950-1957, 2006.

6. Bodine SC, Stitt TN, Gonzalez M, Kline WO, Stover GL, Bauerlein R, Zlotchenko E, Scrimgeour A, Lawrence JC, Glass DJ, and Yancopoulos GD. Akt/mTOR pathway is a crucial regulator of skeletal muscle hypertrophy and can prevent muscle atrophy in vivo. Nat Cell Biol 3: 1014-1019, 2001.

7. Brooke MH, and Kaiser KK. Some comments on the histochemical characterization of muscle adenosine triphosphatase. J Histochem Cytochem 17: 431-432, 1969.

8. Burnett PE, Barrow RK, Cohen NA, Snyder SH, and Sabatini DM. RAFT1 phosphorylation of the translational regulators p70 S6 kinase and 4EBP1. Proc Natl Acad Sci U S A 95: 1432-1437, 1998.

9. Clarke DW, Wrenshall GA, and Mayer J. Effects of pituitary growth hormone on the insulin and hyperglycaemic-glycogenolytic factor extractable from the pancreas of obese-hyperglycaemic mice. Nature 177: 1235, 1956.

10. Corton JM, Gillespie JG, Hawley SA, and Hardie DG. 5aminoimidazole-4-carboxamide ribonucleoside. A specific method for activating AMP-activated protein kinase in intact cells? Eur J Biochem 229: 558-565, 1995.

11. Cunningham JT, Rodgers JT, Arlow DH, Vazquez F, Mootha VK, and Puigserver P. mTOR controls mitochondrial oxidative function through a YY1PGC-1alpha transcriptional complex. Nature 450: 736-740, 2007.

12. Davies SP, Helps NR, Cohen PT, and Hardie DG. 5'-AMP inhibits dephosphorylation, as well as promoting phosphorylation, of the AMP-activated protein kinase. Studies using bacterially expressed human protein phosphatase$2 \mathrm{C}$ alpha and native bovine protein phosphatase-2AC. FEBS Lett 377: 421-425, 1995.

13. Ellisen LW. Growth control under stress: mTOR regulation through the REDD1-TSC pathway. Cell Cycle 4: 1500-1502, 2005.

14. Engel WK. Fiber-type nomenclature of human skeletal muscle for histochemical purposes. Neurology 24: 344-348, 1974.

15. Enser M. Clearing-factor lipase in obese hyperglycaemic mice (ob-ob). Biochem J 129: 447-453, 1972. 
16. Fingar DC, Salama S, Tsou C, Harlow E, and Blenis J. Mammalian cell size is controlled by mTOR and its downstream targets S6K1 and 4EBP1/elF4E. Genes Dev 16: 1472-1487, 2002.

17. Fitch CD, Jellinek M, Fitts RH, Baldwin KM, and Holloszy JO. Phosphorylated beta-guanidinopropionate as a substitute for phosphocreatine in rat muscle. Am J Physiol 228: 1123-1125, 1975.

18. Fitch CD, Jellinek M, and Mueller EJ. Experimental depletion of creatine and phosphocreatine from skeletal muscle. J Biol Chem 249: 1060-1063, 1974.

19. Fitch CD, Shields RP, Payne WF, and Dacus JM. Creatine metabolism in skeletal muscle. 3. Specificity of the creatine entry process. J Biol Chem 243: 2024-2027, 1968.

20. Gaster M. The dynamic of lipid oxidation in human myotubes. Biochim Biophys Acta 1791: 17-24, 2009.

21. Gaster M, Vach W, Beck-Nielsen H, and Schroder HD. GLUT4 expression at the plasma membrane is related to fibre volume in human skeletal muscle fibres. APMIS 110: 611-619, 2002.

22. Gingras AC, Kennedy SG, O'Leary MA, Sonenberg N, and Hay N. 4E$\mathrm{BP} 1$, a repressor of $\mathrm{mRNA}$ translation, is phosphorylated and inactivated by the Akt(PKB) signaling pathway. Genes Dev 12: 502-513, 1998.

23. Ha J, Lee JK, Kim KS, Witters LA, and Kim KH. Cloning of human acetyl-CoA carboxylase-beta and its unique features. Proc Natl Acad Sci U S A 93: 11466-11470, 1996.

24. Hardie DG, and Carling D. The AMP-activated protein kinase--fuel gauge of the mammalian cell? Eur J Biochem 246: 259-273, 1997.

25. Harmon CS, Proud CG, and Pain VM. Effects of starvation, diabetes and acute insulin treatment on the regulation of polypeptide-chain initiation in rat skeletal muscle. Biochem J 223: 687-696, 1984.

26. Harrington LS, Findlay GM, Gray A, Tolkacheva T, Wigfield S, Rebholz H, Barnett J, Leslie NR, Cheng S, Shepherd PR, Gout I, Downes CP, and Lamb RF. The TSC1-2 tumor suppressor controls insulin-PI3K signaling via regulation of IRS proteins. J Cell Biol 166: 213-223, 2004.

27. Harrison BC, and Leinwand LA. Fighting fat with muscle: bulking up to slim down. Cell Metab 7: 97-98, 2008.

28. He J, Watkins S, and Kelley DE. Skeletal muscle lipid content and oxidative enzyme activity in relation to muscle fiber type in type 2 diabetes and obesity. Diabetes 50: 817-823, 2001.

29. Helge JW, Fraser AM, Kriketos AD, Jenkins AB, Calvert GD, Ayre KJ, and Storlien LH. Interrelationships between muscle fibre type, substrate oxidation and body fat. Int J Obes Relat Metab Disord 23: 986-991, 1999.

30. Herbert TP, Tee AR, and Proud CG. The extracellular signal-regulated kinase pathway regulates the phosphorylation of 4E-BP1 at multiple sites. $J$ Biol Chem 277: 11591-11596, 2002.

31. Hickey MS, Carey JO, Azevedo JL, Houmard JA, Pories WJ, Israel RG, and Dohm GL. Skeletal muscle fiber composition is related to adiposity and in vitro glucose transport rate in humans. Am J Physiol 268: E453-457, 1995. 
32. Ingalls AM, Dickie MM, and Snell GD. Obese, a new mutation in the house mouse. J Hered 41: 317-318, 1950.

33. Inoki $\mathrm{K}$, Ouyang $\mathrm{H}$, Zhu $\mathrm{T}$, Lindvall $\mathrm{C}$, Wang $\mathrm{Y}$, Zhang $\mathrm{X}$, Yang $\mathbf{Q}$, Bennett C, Harada Y, Stankunas K, Wang CY, He X, MacDougald OA, You M, Williams BO, and Guan KL. TSC2 integrates Wnt and energy signals via a coordinated phosphorylation by AMPK and GSK3 to regulate cell growth. Cell 126: 955-968, 2006.

34. Jacinto E, Loewith R, Schmidt A, Lin S, Ruegg MA, Hall A, and Hall MN. Mammalian TOR complex 2 controls the actin cytoskeleton and is rapamycin insensitive. Nat Cell Biol 6: 1122-1128, 2004.

35. Janovska A, Hatzinikolas G, Staikopoulos V, Mclnerney J, Mano M, and Wittert GA. AMPK and ACC phosphorylation: effect of leptin, muscle fibre type and obesity. Mol Cell Endocrinol 284: 1-10, 2008.

36. Kawada S, and Ishii $\mathbf{N}$. Changes in skeletal muscle size, fibre-type composition and capillary supply after chronic venous occlusion in rats. Acta Physiol (Oxf) 192: 541-549, 2008.

37. Kelly FJ, and Jefferson LS. Control of peptide-chain initiation in rat skeletal muscle. Development of methods for preparation of native ribosomal subunits and analysis of the effect of insulin on formation of $40 \mathrm{~S}$ initiation complexes. J Biol Chem 260: 6677-6683, 1985.

38. Kemp JG, Blazev R, Stephenson DG, and Stephenson GM. Morphological and biochemical alterations of skeletal muscles from the genetically obese (ob/ob) mouse. Int J Obes (Lond) 33: 831-841, 2009.

39. Kern M, Wells JA, Stephens JM, Elton CW, Friedman JE, Tapscott EB, Pekala PH, and Dohm GL. Insulin responsiveness in skeletal muscle is determined by glucose transporter (Glut4) protein level. Biochem J 270: 397-400, 1990.

40. Khamzina L, Veilleux A, Bergeron S, and Marette A. Increased activation of the mammalian target of rapamycin pathway in liver and skeletal muscle of obese rats: possible involvement in obesity-linked insulin resistance. Endocrinology 146: 1473-1481, 2005.

41. Kimball SR, Do AN, Kutzler L, Cavener DR, and Jefferson LS. Rapid turnover of the mTOR complex 1 (mTORC1) repressor REDD1 and activation of mTORC1 signaling following inhibition of protein synthesis. J Biol Chem 283: 3465-3475, 2008.

42. Koopman R, Schaart G, and Hesselink MK. Optimisation of oil red O staining permits combination with immunofluorescence and automated quantification of lipids. Histochem Cell Biol 116: 63-68, 2001.

43. Koves TR, Ussher JR, Noland RC, Slentz D, Mosedale M, Ilkayeva O, Bain J, Stevens R, Dyck JR, Newgard CB, Lopaschuk GD, and Muoio DM. Mitochondrial overload and incomplete fatty acid oxidation contribute to skeletal muscle insulin resistance. Cell Metab 7: 45-56, 2008.

44. Krebs M, Brunmair B, Brehm A, Artwohl M, Szendroedi J, Nowotny P, Roth E, Furnsinn C, Promintzer M, Anderwald C, Bischof M, and Roden M. The Mammalian target of rapamycin pathway regulates nutrient-sensitive glucose uptake in man. Diabetes 56: 1600-1607, 2007. 
45. Kumar V, Pandey P, Sabatini D, Kumar M, Majumder PK, Bharti A, Carmichael G, Kufe D, and Kharbanda S. Functional interaction between RAFT1/FRAP/mTOR and protein kinase cdelta in the regulation of capdependent initiation of translation. EMBO J 19: 1087-1097, 2000.

46. Le Bacquer O, Petroulakis E, Paglialunga S, Poulin F, Richard D, Cianflone K, and Sonenberg $\mathbf{N}$. Elevated sensitivity to diet-induced obesity and insulin resistance in mice lacking 4E-BP1 and 4E-BP2. J Clin Invest 117: 387396, 2007.

47. Levin K, Daa Schroeder H, Alford FP, and Beck-Nielsen H. Morphometric documentation of abnormal intramyocellular fat storage and reduced glycogen in obese patients with Type II diabetes. Diabetologia 44: 824833, 2001.

48. Mahlapuu M, Johansson C, Lindgren K, Hjalm G, Barnes BR, Krook A, Zierath JR, Andersson L, and Marklund S. Expression profiling of the gamma-subunit isoforms of AMP-activated protein kinase suggests a major role for gamma3 in white skeletal muscle. Am J Physiol Endocrinol Metab 286: E194200, 2004.

49. Mayer J, Bates MW, and Dickie MM. Hereditary diabetes in genetically obese mice. Science 113: 746-747, 1951.

50. Mayer J, Dickie MM, Bates MW, and Vitale JJ. Free selection of nutrients by hereditarily obese mice. Science 113: 745-746, 1951.

51. Mayer J, Russell RE, Bates MW, and Dickie MM. Basal oxygen consumption of hereditarily obese and diabetic mice. Endocrinology 50: 318-323, 1952.

52. McManus EJ, Sakamoto K, Armit LJ, Ronaldson L, Shpiro N, Marquez $\mathbf{R}$, and Alessi DR. Role that phosphorylation of GSK3 plays in insulin and Wnt signalling defined by knockin analysis. EMBO J 24: 1571-1583, 2005.

53. Meglasson MD, Wilson JM, Yu JH, Robinson DD, Wyse BM, and de Souza CJ. Antihyperglycemic action of guanidinoalkanoic acids: 3guanidinopropionic acid ameliorates hyperglycemia in diabetic KKAy and C57BL6Job/ob mice and increases glucose disappearance in rhesus monkeys. $J$ Pharmacol Exp Ther 266: 1454-1462, 1993.

54. Miller AM, Brestoff JR, Phelps CB, Berk EZ, and Reynolds THt. Rapamycin does not improve insulin sensitivity despite elevated mammalian target of rapamycin complex 1 activity in muscles of ob/ob mice. Am J Physiol Regul Integr Comp Physiol 295: R1431-1438, 2008.

55. Miyazaki M, and Esser KA. REDD2 is enriched in skeletal muscle and inhibits mTOR signaling in response to leucine and stretch. Am J Physiol Cell Physiol 296: C583-592, 2009.

56. Moro C, Galgani JE, Luu L, Pasarica M, Mairal A, Bajpeyi S, Schmitz G, Langin D, Liebisch G, and Smith SR. Influence of gender, obesity, and muscle lipase activity on intramyocellular lipids in sedentary individuals. $J$ Clin Endocrinol Metab 94: 3440-3447, 2009.

57. Newgard CB, An J, Bain JR, Muehlbauer MJ, Stevens RD, Lien LF, Haqq AM, Shah SH, Arlotto M, Slentz CA, Rochon J, Gallup D, Ilkayeva O, Wenner BR, Yancy WS, Jr., Eisenson H, Musante G, Surwit RS, Millington 
DS, Butler MD, and Svetkey LP. A branched-chain amino acid-related metabolic signature that differentiates obese and lean humans and contributes to insulin resistance. Cell Metab 9: 311-326, 2009.

58. Oakes ND, Bell KS, Furler SM, Camilleri S, Saha AK, Ruderman NB, Chisholm DJ, and Kraegen EW. Diet-induced muscle insulin resistance in rats is ameliorated by acute dietary lipid withdrawal or a single bout of exercise: parallel relationship between insulin stimulation of glucose uptake and suppression of long-chain fatty acyl-CoA. Diabetes 46: 2022-2028, 1997.

59. Ouchi N, Shibata R, and Walsh K. AMP-activated protein kinase signaling stimulates VEGF expression and angiogenesis in skeletal muscle. Circ Res 96: 838-846, 2005.

60. Patti ME, Brambilla E, Luzi L, Landaker EJ, and Kahn CR. Bidirectional modulation of insulin action by amino acids. J Clin Invest 101: 1519-1529, 1998.

61. Payne CM, Stern LZ, Curless RG, and Hannapel LK. Ultrastructural fiber typing in normal and diseased human muscle. J Neurol Sci 25: 99-108, 1975.

62. Peterson JM, Bryner RW, and Alway SE. Satellite cell proliferation is reduced in muscles of obese Zucker rats but restored with loading. Am J Physiol Cell Physiol 295: C521-528, 2008.

63. Purchas RW, Romsos DR, Allen RE, and Merkel RA. Muscle growth and satellite cell proliferative activity in obese (OB/OB) mice. J Anim Sci 60: 644651, 1985.

64. Rannels DE, Pegg AE, Rannels SR, and Jefferson LS. Effect of starvation on initiation of protein synthesis in skeletal muscle and heart. $A m \mathrm{~J}$ Physiol 235: E126-133, 1978.

65. Raught B, Peiretti F, Gingras AC, Livingstone M, Shahbazian D, Mayeur GL, Polakiewicz RD, Sonenberg N, and Hershey JW. Phosphorylation of eucaryotic translation initiation factor 4B Ser422 is modulated by S6 kinases. EMBO J 23: 1761-1769, 2004.

66. Reznick RM, Zong H, Li J, Morino K, Moore IK, Yu HJ, Liu ZX, Dong J, Mustard KJ, Hawley SA, Befroy D, Pypaert M, Hardie DG, Young LH, and Shulman GI. Aging-associated reductions in AMP-activated protein kinase activity and mitochondrial biogenesis. Cell Metab 5: 151-156, 2007.

67. Rivas DA, Yaspelkis BB, 3rd, Hawley JA, and Lessard SJ. Lipidinduced mTOR activation in rat skeletal muscle reversed by exercise and 5'aminoimidazole-4-carboxamide-1-beta-D-ribofuranoside. J Endocrinol 202: 441451, 2009.

68. Roden M, Price TB, Perseghin G, Petersen KF, Rothman DL, Cline GW, and Shulman GI. Mechanism of free fatty acid-induced insulin resistance in humans. J Clin Invest 97: 2859-2865, 1996.

69. Sarbassov DD, Ali SM, Kim DH, Guertin DA, Latek RR, ErdjumentBromage H, Tempst P, and Sabatini DM. Rictor, a novel binding partner of mTOR, defines a rapamycin-insensitive and raptor-independent pathway that regulates the cytoskeleton. Curr Biol 14: 1296-1302, 2004. 
70. Sarbassov DD, Guertin DA, Ali SM, and Sabatini DM. Phosphorylation and regulation of Akt/PKB by the rictor-mTOR complex. Science 307: 1098-1101, 2005.

71. Schieke SM, Phillips D, McCoy JP, Jr., Aponte AM, Shen RF, Balaban RS, and Finkel T. The mammalian target of rapamycin (mTOR) pathway regulates mitochondrial oxygen consumption and oxidative capacity. J Biol Chem 281: 27643-27652, 2006.

72. Shargill NS, Ohshima K, Bray GA, and Chan TM. Muscle protein turnover in the perfused hindquarters of lean and genetically obese-diabetic (db/db) mice. Diabetes 33: 1160-1164, 1984.

73. Shields RP, and Whitehair CK. Muscle creatine: in vivo depletion by feeding beta-guanidinopropionic acid. Can J Biochem 51: 1046-1049, 1973.

74. Sinha R, Dufour S, Petersen KF, LeBon V, Enoksson S, Ma YZ, Savoye M, Rothman DL, Shulman GI, and Caprio S. Assessment of skeletal muscle triglyceride content by $(1) \mathrm{H}$ nuclear magnetic resonance spectroscopy in lean and obese adolescents: relationships to insulin sensitivity, total body fat, and central adiposity. Diabetes 51: 1022-1027, 2002.

75. Sparrow MP, Earl CA, Laurent GL, and Everett AW. Turnover rates of muscle proteins in cardiac, skeletal, and smooth muscle: turnover rate related to muscle function. Recent Adv Stud Cardiac Struct Metab 12: 29-34, 1976.

76. Steinberg GR, Macaulay SL, Febbraio MA, and Kemp BE. AMPactivated protein kinase--the fat controller of the energy railroad. Can $\mathrm{J}$ Physiol Pharmacol 84: 655-665, 2006.

77. Steinberg GR, Rush JW, and Dyck DJ. AMPK expression and phosphorylation are increased in rodent muscle after chronic leptin treatment. Am J Physiol Endocrinol Metab 284: E648-654, 2003.

78. Svanberg E, Jefferson LS, Lundholm K, and Kimball SR. Postprandial stimulation of muscle protein synthesis is independent of changes in insulin. Am J Physiol 272: E841-847, 1997.

79. Svanberg E, Zachrisson H, Ohlsson C, Iresjo BM, and Lundholm KG. Role of insulin and IGF-I in activation of muscle protein synthesis after oral feeding. Am J Physiol 270: E614-620, 1996.

80. Takata M, Ogawa W, Kitamura T, Hino Y, Kuroda S, Kotani K, Klip A, Gingras AC, Sonenberg N, and Kasuga M. Requirement for Akt (protein kinase $B$ ) in insulin-induced activation of glycogen synthase and phosphorylation of $4 \mathrm{E}$ BP1 (PHAS-1). J Biol Chem 274: 20611-20618, 1999.

81. Tanner CJ, Barakat HA, Dohm GL, Pories WJ, MacDonald KG, Cunningham PR, Swanson MS, and Houmard JA. Muscle fiber type is associated with obesity and weight loss. Am J Physiol Endocrinol Metab 282: E1191-1196, 2002.

82. Taube A, Eckardt $\mathrm{K}$, and Eckel $\mathrm{J}$. Role of lipid-derived mediators in skeletal muscle insulin resistance. Am J Physiol Endocrinol Metab 2009.

83. Thampy KG, and Wakil SJ. Activation of acetyl-CoA carboxylase. Purification and properties of a Mn2+-dependent phosphatase. J Biol Chem 260: 6318-6323, 1985. 
84. Trayhurn $\mathbf{P}$, Wang $\mathbf{B}$, and Wood IS. Hypoxia in adipose tissue: a basis for the dysregulation of tissue function in obesity? Br J Nutr 100: 227-235, 2008.

85. Tremblay F, Krebs M, Dombrowski L, Brehm A, Bernroider E, Roth E, Nowotny P, WaldhausI W, Marette A, and Roden M. Overactivation of S6 kinase 1 as a cause of human insulin resistance during increased amino acid availability. Diabetes 54: 2674-2684, 2005.

86. Tsang CK, Qi H, Liu LF, and Zheng XF. Targeting mammalian target of rapamycin (mTOR) for health and diseases. Drug Discov Today 12: 112-124, 2007.

87. Tsika RW, Herrick RE, and Baldwin KM. Time course adaptations in rat skeletal muscle isomyosins during compensatory growth and regression. $J \mathrm{Appl}$ Physiol 63: 2111-2121, 1987.

88. Turpin SM, Ryall JG, Southgate R, Darby I, Hevener AL, Febbraio MA, Kemp BE, Lynch GS, and Watt MJ. Examination of 'lipotoxicity' in skeletal muscle of high-fat fed and ob/ob mice. J Physiol 587: 1593-1605, 2009.

89. Tzatsos A. Raptor binds the SAIN (Shc and IRS-1 NPXY binding) domain of insulin receptor substrate-1 (IRS-1) and regulates the phosphorylation of IRS-1 at Ser-636/639 by mTOR. J Biol Chem 284: 22525-22534, 2009.

90. Um SH, Frigerio F, Watanabe $\mathbf{M}$, Picard F, Joaquin $\mathbf{M}$, Sticker $\mathbf{M}$, Fumagalli S, Allegrini PR, Kozma SC, Auwerx J, and Thomas G. Absence of S6K1 protects against age- and diet-induced obesity while enhancing insulin sensitivity. Nature 431: 200-205, 2004.

91. von Manteuffel SR, Gingras AC, Ming XF, Sonenberg N, and Thomas G. 4E-BP1 phosphorylation is mediated by the FRAP-p70s6k pathway and is independent of mitogen-activated protein kinase. Proc Natl Acad Sci U S A 93: 4076-4080, 1996.

92. Wang H, Kubica N, Ellisen LW, Jefferson LS, and Kimball SR. Dexamethasone represses signaling through the mammalian target of rapamycin in muscle cells by enhancing expression of REDD1. J Biol Chem 281: 3912839134, 2006.

93. Wende AR, Schaeffer PJ, Parker GJ, Zechner C, Han DH, Chen MM, Hancock CR, Lehman JJ, Huss JM, McClain DA, Holloszy JO, and Kelly DP. A role for the transcriptional coactivator PGC-1alpha in muscle refueling. $J$ Biol Chem 282: 36642-36651, 2007.

94. Wensaas AJ, Rustan AC, Just M, Berge RK, Drevon CA, and Gaster M. Fatty acid incubation of myotubes from humans with type 2 diabetes leads to enhanced release of beta-oxidation products because of impaired fatty acid oxidation: effects of tetradecylthioacetic acid and eicosapentaenoic acid. Diabetes 58: 527-535, 2009.

95. Williams DB, Sutherland LN, Bomhof MR, Basaraba SA, Thrush AB, Dyck DJ, Field CJ, and Wright DC. Muscle-specific differences in the response of mitochondrial proteins to beta-GPA feeding: an evaluation of potential mechanisms. Am J Physiol Endocrinol Metab 296: E1400-1408, 2009.

96. Winder WW, and Hardie DG. AMP-activated protein kinase, a metabolic master switch: possible roles in type 2 diabetes. Am J Physiol 277: E1-10, 1999. 
97. Yu C, Chen Y, Cline GW, Zhang D, Zong H, Wang Y, Bergeron R, Kim JK, Cushman SW, Cooney GJ, Atcheson B, White MF, Kraegen EW, and Shulman GI. Mechanism by which fatty acids inhibit insulin activation of insulin receptor substrate-1 (IRS-1)-associated phosphatidylinositol 3-kinase activity in muscle. J Biol Chem 277: 50230-50236, 2002.

98. Zawalich WS, Tesz GJ, and Zawalich KC. Inhibitors of phosphatidylinositol 3-kinase amplify insulin release from islets of lean but not obese mice. J Endocrinol 174: 247-258, 2002.

99. Zhang HH, Lipovsky Al, Dibble CC, Sahin M, and Manning BD. S6K1 regulates GSK3 under conditions of mTOR-dependent feedback inhibition of Akt. Mol Cell 24: 185-197, 2006. 


\section{Curriculum Vitae}

Joshua C. Drake

Work Address:

Division of Exercise Physiology

1 Medical Center Drive

West Virginia University School of Medicine

P.O. Box 9227

Morgantown, WV 26506

jdrake4@mix.wvu.edu (email)
Home Address:

50 St. Clair's Village

Morgantown, WV 26505

(304) 561-4387

\section{Education:}

\begin{tabular}{lll}
\hline$\quad 2008-2010$ & West Virginia University & M.S. Exercise \\
& & Physiology \\
- 2002-2007 & West Virginia University & B.S. Exercise \\
& & Physiology
\end{tabular}

\section{Professional Experience}

$\begin{array}{llll}\text { - } 2007-\text { present } & \text { Carmichael Training Systems } & \text { Expert Coach } \\ \text { Health South Mountainview } & \begin{array}{l}\text { Physical Therapy } \\ \text { Aide }\end{array} \\ \text { - 2006-2004 } & \text { Tri-County YMCA } & \begin{array}{l}\text { Life guard \& } \\ \text { Swim Instructor }\end{array}\end{array}$

\section{Educational Experience}

\begin{tabular}{|c|c|c|c|}
\hline - & 2008-present & West Virginia University & Research Assistant \\
\hline & & & to Dave \\
\hline & & & Williamson \\
\hline & & & Ph.D. \\
\hline - & Fall 2008 & West Virginia University & $\begin{array}{l}\text { Clinical Assistant } \\
\text { in Human }\end{array}$ \\
\hline & & & Performance Lab \\
\hline - & 2006 & Missions Trip & Ryazan, Russia \\
\hline & & $\begin{array}{l}\text { ned general maintenance } \\
\text { urches, served an orphana } \\
\text { for girls ages } 12-22 \text {. }\end{array}$ & $\begin{array}{l}\text { onstruction work on } \\
\text { side of the city and a }\end{array}$ \\
\hline
\end{tabular}


- $2006 \quad$ Missions Trip Wewahitchka, FL

- Performed general maintenance and construction work on an orphanage as well as organized activities and games for the kids.

\section{Abstracts/Presentations}

- AICAR Treatment Alters Skeletal Muscle Mass Regulatory Processes in OB/OB Mice. Williamson, D., Drake, J. Presented at the 2009 International Biochemistry of Exercise Conference in Guelph, Ontario, Canada. 